\title{
Zonal Organization of the Flocculovestibular Nucleus Projection in the Rabbit: A Combined Axonal Tracing and Acetylcholinesterase Histochemical Study
}

\author{
J. TAN, A.H. EPEMA, AND J. VOOGD \\ Department of Anatomy, Erasmus University Rotterdam, 3000 DR Rotterdam, \\ The Netherlands (J.T., J.V.) and Department of Anesthesiology, Academic Hospital, \\ University of Groningen, Groningen, The Netherlands (A.H.E.)
}

\begin{abstract}
With the use of retrograde transport of horseradish peroxidase we confirmed the observation of Yamamoto and Shimoyama ([1977] Neurosci Lett. 5:279-283) that Purkinje cells of the rabbit flocculus projecting to the medial vestibular nucleus are located in two discrete zones, $\mathrm{FZ}_{\mathrm{II}}$ and $\mathrm{FZ}_{\mathrm{IV}}$, that alternate with two other Purkinje cell zones, $\mathrm{FZ}_{\mathrm{I}}$ and $\mathrm{FZ}_{\mathrm{III}}$, projecting to the superior vestibular nucleus. The retrogradely labeled axons of these Purkinje cells collect in four bundles that occupy the corresponding floccular white matter compartments, $\mathrm{FC}_{1-4}$, that can be delineated with acetylcholinesterase histochemistry (Tan et al. [1995a] J. Comp. Neurol., this issue). Anterograde tracing from small injections of wheat germ agglutin-hoseradish peroxidase in single Purkinje cell zones of the flocculus showed that Purkinje cell axons of $\mathrm{FZ}_{\mathrm{II}}$ travel in $\mathrm{FC}_{2}$ to terminate in the medial vestibular nucleus. Purkinje cell axons from $\mathrm{FZ}_{1}$ and $\mathrm{FZ}_{\mathrm{III}}$ occupy the $\mathrm{FC}_{1}$ and $\mathrm{FC}_{3}$ compartments, respectively, and terminate in the superior vestibular nucleus. Purkinje cell axons from all three compartments pass through the floccular peduncle and dorsal group $\mathrm{y}$. In addition, some fibers from $\mathrm{FZ}_{\mathrm{I}}$ and $\mathrm{FZ}_{\mathrm{II}}$, but not from $\mathrm{FZ}_{\mathrm{III}}$, arch through the cerebellar nuclei to join the floccular peduncle more medially. No anterograde tracing experiments were available to determine the projections of the $\mathrm{FZ}_{\mathrm{IV}}$ and $\mathrm{C}_{2}$ zones. The functional implications of these results are discussed. 1995 Wiley-Liss, Inc.
\end{abstract}

Indexing terms: cerebellum, corticonuclear projection, Purkinje cell, group y, eye movements

The flocculus plays an important role in the control of eye movements by processing visual and vestibular information (Robinson, 1976; Ito et al., 1982a; Nagao, 1983; Ito, 1984). Via their projections to the vestibular nuclei, Purkinje cells of the flocculus inhibit certain groups of vestibulo-ocular relay cells (Ito et al., 1970; Baker et al., 1972; Fukuda et al., 1972; Highstein, 1973; Kawaguchi, 1985; Sato and Kawasaki, 1987, 1990a,b, 1991; Sato et al., 1988). The projection of the flocculus to the vestibular nuclei has been known since the studies of Dow $(1936,1938 \mathrm{a}, \mathrm{b})$ using the Marchi method in rat, cat, and monkey. Recent studies using modern tracing techniques showed that the flocculus sends major projections to the superior (SV) and medial vestibular nucleus (MV), group $y$, the lateral cerebellar nucleus (LCN), and the basal interstitial nucleus and minor projections to the descending vestibular nucleus (DV) and the nucleus prepositus hypoglossi (Jansen and Brodal, 1940; Voogd, 1964; Angaut and Brodal, 1967; Alley, 1977; Haines, 1977; Yamamoto and Shimoyama, 1977; Balaban et al., 1981; Sato et al., 1982a,b; Carpenter and Cowie, 1985;
Langer et al., 1985; Epema, 1990). Some of these studies have indicated that the Purkinje cell population of the flocculus consists of subsets arranged in zones that cross the folia of the flocculus and project to different vestibular nuclei.

Yamamoto and Shimoyama (1977) found that the Purkinje cells of the flocculus of the rabbit that project to MV and SV are distributed in a striped pattern. They distinguished two Purkinje cell zones projecting to MV and two zones projecting to SV. The two zones projecting to MV are interleaved with the two zones projecting to SV; the most rostral of these four zones projects to MV. Purkinje cells of a fifth zone, located in the caudal flocculus and also extending into folium $\mathrm{p}$, were labeled from injections of horseradish peroxidase (HRP) in the lateral cerebellar nucleus (Yamamoto, 1978). In her later publications (Yama-

\section{Accepted September 9, 1994}

Address reprint requests to J. Voogd, Department of Anatomy, Erasmus University Rotterdam, P.O. Box 1738, 3000 DR Rotterdam, The Netherlands. 
moto, 1978, 1979a,b), the rostral MV zone was no longer mentioned. A single MV zone, flanked by two SV-projecting zones also was distinguished in monkeys (Balaban et al., 1981). A different pattern of efferent connections was described for the three zones in the flocculus of the cat by Sato et al. (1982a,b). Their rostral zone projected to SV, the middle zone to $\mathrm{MV}$, and the caudal zone to group $\mathrm{y}$ and sparsely to the parvicellular lateral cerebellar nucleus.

Similar zonal patterns were revealed by microstimulation of the rabbit flocculus and recording of the inhibition of specific vestibulo-ocular reflex pathways (Yamamoto, 1979b; Ito et al., 1982b). Local electrical stimulation elicited eye movements (Dufossé et al., 1977; Balaban and Watanabe, 1984; Nagao et al., 1985; Belknap and Noda, 1987; Sato and Kawasaki, 1990a, 1991). In the rabbit, microstimulation in the Purkinje cell layer of the flocculus resulted in horizontal, vertical, and rotatory eye movements located in four zones (Dufossé et al., 1977; Nagao et al., 1985). An H-zone, in which electrical stimulation elicited horizontal eye movements, was flanked by two V-zones in which stimulation elicited vertical eye movements. This trizonal organization of eye movement control has also been found in cat (Sato and Kawasaki, 1984, 1990a,b, 1991; Sato et al., 1984) and monkey (Balaban and Watanabe, 1984). In rabbit the zonal organization was complicated by the presence of rotatory eye movements on stimulation of an R-zone, which overlapped large parts of the $\mathrm{H}$ - and V-zones (Ito et al., 1982b, Nagao et al., 1985). The functional representation of eye movements in zones probably reflects the zonal arrangement in the efferent and afferent (climbing fiber) connections of the Purkinje cells. Precise correlations of the functional and anatomical properties of the floccular zones are hindered by inconsistencies between the different anatomical and physiological studies on the number and extent of the zones, by large individual variations in the number and size of the folia of the flocculus, and by differences in zonal organization between different species.

Recently, a morphological zonation in the rabbit flocculus has been demonstrated using acetylcholinesterase (AChE) histochemistry (Tan et al., 1995a). AChE-positive raphes subdivide the white matter of the flocculus into five compartments. In a previous study (Tan et al, 1995b) the AChE compartmentation was used as an independent reference to correlate data from experiments on the olivocerebellar projection to the rabbit flocculus. The climbing fibers terminate in five zones, $\mathrm{FZ}_{\mathrm{I}-\mathrm{IV}}$ and $\mathrm{C}_{2}$, each of which is associated with a particular white matter compartment $\left(\mathrm{FC}_{1-4}, \mathrm{C}_{2}\right)$. The rostral dorsal cap (rdc) and adjacent ventrolateral outgrowth (vlo) supply climbing fibers to $\mathrm{FZ}_{\mathrm{I}}$ and $\mathrm{FZ}_{\text {III }}$ via compartments $\mathrm{FC}_{1}$ and $\mathrm{FC}_{3}$, the caudal dorsal cap (cdc) supplies $\mathrm{FZ}_{\mathrm{II}}$ and $\mathrm{FZ}_{\mathrm{IV}}$ via $\mathrm{FC}_{2}$ and $\mathrm{FC}_{4}$, and the rostral medial accessory olive innervates zone $\mathrm{C}_{2}$ via compartment $\mathrm{C}_{2}$.

In this study we investigated, with anterograde and retrograde transport methods, the differential projection of Purkinje cells of the floccular zones $\mathrm{FZ}_{1-\mathrm{IV}}$ to the vestibular and cerebellar nuclei and the relation of their axons to the white matter compartmentation as described by Tan et al. (1989, 1995a). Recently, Purkinje cell axons from identified zones were also traced with biocytin by De Zeeuw et al. $(1992,1994 \mathrm{~b})$.

\section{MATERIALS AND METHODS Retrograde studies}

Horseradish peroxidase $(33 \%)$ dissolved in phosphatebuffered saline was pressure injected within the vestibular nuclei of halothane-anesthetized rabbits with a 1- $\mu$ l Hamilton syringe and a 25-gauge needle (Epema, 1990). Two of these cases will be presented: one with an injection in the SV [case C $253(0.1 \mu \mathrm{l})]$ and one in the MV [C $480(1.0 \mu \mathrm{l})]$. After a survival time of 2 days the animals were heparinized and transcardially perfused under deep anesthesia with 0.5 liter of saline, followed by 1.5 liters of citrate buffer $(0.1 \mathrm{M}$, $\mathrm{pH} 7.4$ ) containing $1 \%$ formaldehyde and $1.25 \%$ glutaraldehyde and subsequently washed with 0.5 liter of citrate buffer $(0.1 \mathrm{M}, \mathrm{pH} 7.4$ ) containing $8 \%$ sucrose (Mesulam, 1978). The brains were removed, embedded in $10 \%$ gelatin (Voogd and Feirabend, 1981), and transversely sectioned at $40 \mu \mathrm{m}$. A series containing one of every four sections was incubated with diamonobenzidine (DAB; Graham and Karnovsky, 1966) and counterstained with cresyl violet.

\section{Anterograde studies}

Nine pigmented Dutch belted rabbits were anesthetized by an initial intramuscular injection of a mixture of ketamine $(32 \mathrm{mg} / \mathrm{kg})$, acepromazine $(0.32 \mathrm{mg} / \mathrm{kg})$, and xylazine $(5 \mathrm{mg} / \mathrm{kg})$. Supplements were given every $30-45$ minutes $(9 \mathrm{mg} / \mathrm{kg}$ ketamine, $0,09 \mathrm{mg} / \mathrm{kg}$ acepromazine, 2 $\mathrm{mg} / \mathrm{kg}$ xylazine). Small quantities $(5-15 \mathrm{nl}$ ) of a $7 \%$ solution in physiological saline of HRP coupled to wheat germ

Abbreviations

$\begin{array}{ll}\text { be } & \text { brachium conjunctivum } \\ \text { bp } & \text { brachium pontis } \\ \mathrm{C}_{2} & \mathrm{C}_{2} \text { zone and compartment } \\ \mathrm{cdc} & \text { caudal dorsal cap } \\ \mathrm{CO} & \text { cochlear nucleus } \\ \mathrm{DV} & \text { descending vestibular nucleus } \\ \mathrm{F} & \text { fastigial nucleus } \\ \mathrm{FC} & \text { floccular compartments 1-4 } \\ \mathrm{FLO} & \text { flocculus } \\ \text { fm } & \text { folium m } \\ \text { fp } & \text { folium } \mathrm{p} \\ \mathrm{f} 1 & \text { folium } 1 \\ \mathrm{f} 2 & \text { folium } 2 \\ \text { f3 } & \text { folium } 3 \\ \mathrm{f} 4 & \text { folium } 4 \\ \mathrm{FZ} & \text { floccular zones I-IV } \\ \text { IA } & \text { anterior interposed nucleus } \\ \text { IP } & \text { posterior interposed nucleus } \\ \mathrm{L} & \text { lateral cerebellar nucleus }\end{array}$

$\begin{array}{ll}\text { lö } & \text { Löwy's fiber bundle } \\ \text { Lpc } & \text { parvicellular part of the lateral cerebellar nucleus } \\ \text { LV } & \text { lateral vestibular nucleus } \\ \mathrm{m} & \text { folium m } \\ \text { MV } & \text { medial vestibular nucleus } \\ \text { MVmc } & \text { magnocellular medial vestibular nucleus } \\ \mathrm{p} & \text { folium } p \\ \mathrm{pf} & \text { floccular peduncle } \\ \text { PFLv } & \text { ventral parafloceulus } \\ \text { PH } & \text { nucleus prepositus hypoglossi } \\ \text { rb } & \text { restiform body } \\ \text { rdc } & \text { rostral dorsal cap } \\ \text { SV } & \text { superior vestibular nucleus } \\ \text { vlo } & \text { ventrolateral outgrowth } \\ \text { y } & \text { group y } \\ \text { VI } & \text { abducens nucleus } \\ \text { VII } & \text { facial nerve } \\ \text { VIII } & \text { vestibulocochlear nerve }\end{array}$


agglutinin (WGA-HRP, Sigma type VI) were injected into the flocculus with air pressure applied to a micropipette. Processing of the transversely sectioned brains for tetramethylbenzidine (TMB), DAB, and AChE has been described by Tan et al. (1995a,b).

In some cases ( $\mathrm{K} 301, \mathrm{~K} 305, \mathrm{~K} 340, \mathrm{~K} 355, \mathrm{~K} 360$, and $\mathrm{K}$ 370) the injection sites were determined by recording climbing fiber responses of the Purkinje cells to rotating random dot patterns (Graf et al., 1988; Leonard et al., 1988). Injection sites are indicated in maps of the unfolded flocculus Fig. 1). When the flocculus was unfolded, the length of the Purkinje cell layer in single transverse sections was indicated as a straight line. The sections were aligned using the distance from the midline $(\mathrm{M})$ to the most ventromedial point of the Purkinje cell layer of the flocculus (point B in Fig. 1). The distance between the sections ( $t$ ) corresponds to the true distance between the reconstructed sections multiplied by the magnification factor. 'The maps of the flocculus are positioned as viewed from the lateral side; the location and extent of the injection sites, the interfolial fissures, and the approximate position of the climbing fiber zones, estimated by extrapolating the $\mathrm{AChE}$ raphes to the Purkinje cell layer, were indicated (Figs. 1, 6,8).

The labeled fibers in the cerebellum and brainstem were plotted. Their position in the white matter of the flocculus was determined with respect to the borders of the white matter compartments (the raphes) in adjacent $\mathrm{AChE}$ stained sections. The subdivision and nomenclature of the vestibular complex used in the present study is according to Epema et al. (1988) and Tan et al. (1995a). Folia of the flocculus are numbered from ventral to dorsal as fm and $\mathrm{f1}-\mathrm{f} 4$. The folium of the ventral paraflocculus bordering $\mathrm{f} 4$ is called folium p (fp; Yamamoto and Shimoyama, 1977). The five compartments in the floccular white matter are indicated from lateral to medial as $\mathrm{C}_{2}$ and $\mathrm{FC}_{1-4}$ and the corresponding climbing fiber and Purkinje cell zones as $\mathrm{C}_{2}$ and $\mathrm{FZ}_{\mathrm{I}-\mathrm{IV}}$ (Tan et al., 1995a,b).

\section{RESULTS Retrograde experiments}

In $\mathrm{C} 480$ the HRP injection involved all parts of the MV and the ventromedial portion of the LV. Retrogradely labeled Purkinje cells are found in all folia of the flocculus. Two distinct zones of Purkinje cells were labeled; the one located rostrally and medially contained few labeled cells (Fig. 2a-c). The second zone was located more laterally and caudally and remained separated from the rostromedial zone by a band of unlabeled cells. It extended into the rostral tip of folium $p$ (Fig. $2 a-e$ ). More caudally, scattered groups of labeled Purkinje cells were present in folium $p$ (Fig. 2f-j). Thick, retrogradely labeled Purkinje cell axons could be traced from the labeled Purkinje cells, through the granular layer into the white matter. Labeled collaterals detach from the Purkinje cell axons in the granular layer and constitute a plexus at the level of the labeled Purkinje cell somata. Mossy fibers in the granular layer remained unlabeled, and no signs of anterograde axonal transport of HRP were detected. Each Purkinje cell zone was associated with retrograde labeling in a certain part of the white matter. Labeled axons originating from the medial zone of labeled Purkinje cells were present along the rostromedial border of the flocculus with the brachium pontis (Figs. 2b-d, 4A: $\mathrm{FC}_{4}$ ). More caudally they assembled in a bundle at the ventromedial tip of the flocculus, dorsal to the cochlear nuclei (Fig. 2d,e). Labeled axons from the lateral zone of labeled Purkinje cells extended from folium $p$ dorsally to folium $\mathrm{f} 2$ ventrally (Fig. $2 d$ ). More caudally they collected into a triangular bundle, with its base resting on the cortex of $\mathrm{f1}$ (Figs. 2e, 4B: $\mathrm{FC}_{2}$ ). The topography of the labeled compartments corresponds with the $\mathrm{FC}_{4}$ and $\mathrm{FC}_{2}$ compartments delineated in AChE-incubated tissue sections ( $\mathrm{T}$ an et al., 1995a). In the caudal flocculus the labeled fibers could no longer be distinguished as two separate compartments (Figs. 2f,g, 4C). 'The retrogradely labeled axons entered the floccular peduncle in bundles, passing between unlabeled Purkinje cell axons of other compartments. The majority of the labeled fibers could be traced, through the floccular peduncle and group $y$, to the injection site in the MV nucleus. Some labeled fibers entered the dorsal part of the cochlear nucleus. Other bundles of retrogradely labeled fibers arched through the ventral part of the lateral and anterior interposed cerebellar nuclei (Figs. 2g-i, 4C). Most of these fibers passed dorsal to the parvicellular part of the lateral nucleus. More medially they turned sharply ventrally to reach the MV through the caudal pole of the SV. A great number of retrogradely filled axons from labeled Purkinje cells in the anterior and posterior vermis passed through the fastigial nucleus and the medial portion of the anterior and posterior interposed nuclei in the direction of the injection site (Fig. 2f-j). Mossy fiber labeling was not observed.

In case C 253 the injection site was situated in the SV and LV, touching upon the MV (Fig. 3d-i). The injection extended into the ventral part of the superior cerebellar peduncle. Purkinje cells, their axons, and the axon collaterals were retrogradely labeled; no signs of anterograde axonal transport of HRP were observed. Retrogradely labeled Purkinje cells in the flocculus were distributed in two wide zones, separated by an empty strip (Fig. 3b-g). Purkinje cells located along the rostromedial edge of the flocculus remained unlabeled. Labeling of Purkinje cells of both zones extended into folium p (Fig. 3c-f). The labeled Purkinje cells of the two zones gave rise to two bundles of retrogradely filled axons that traveled caudally in the white matter of the flocculus (Figs. $3 \mathrm{~b}-\mathrm{g}$ ). The medial bundle remained separated from the medial border of the flocculus by an empty space, corresponding to $\mathrm{FC}_{4}$, which contained labeled axons in the previous case with an injection of MV. Dorsally in the white matter of folium $p$ the two bundles became fused; ventrally they were separated by a triangular area containing a few labeled fibers and corresponding to the $\mathrm{FC}_{2}$ compartment (Figs. $3 \mathrm{~d}-\mathrm{g}, 5$ ). The most lateral parts of the white matter of folia $\mathrm{f} 1-2$ remained free of retrogradely labeled axons (Fig. $3 \mathrm{e}-\mathrm{g}$ ). This region corresponds to the $\mathrm{C}_{2}$ compartment. From the caudal flocculus labeled fibers could be traced into the floccular peduncle in bundles, passing between unlabeled fibers of the floccular white matter. They passed through dorsal group y to reach the injection site in SV (Fig. 5). Other fibers followed a more dorsal route, through the lateral cerebellar nucleus. Their final course was difficult to establish, because thick, retrogradely filled axons of the superior cerebellar peduncle and retrogradely labeled cells dominated the picture of the lateral and interposed nuclei. Purkinje cells of the vermis and their axons were also retrogradely labeled from this injection site.

\section{Anterograde experiments}

The cases were grouped according to the white matter compartment in which the labeled fibers were located and 

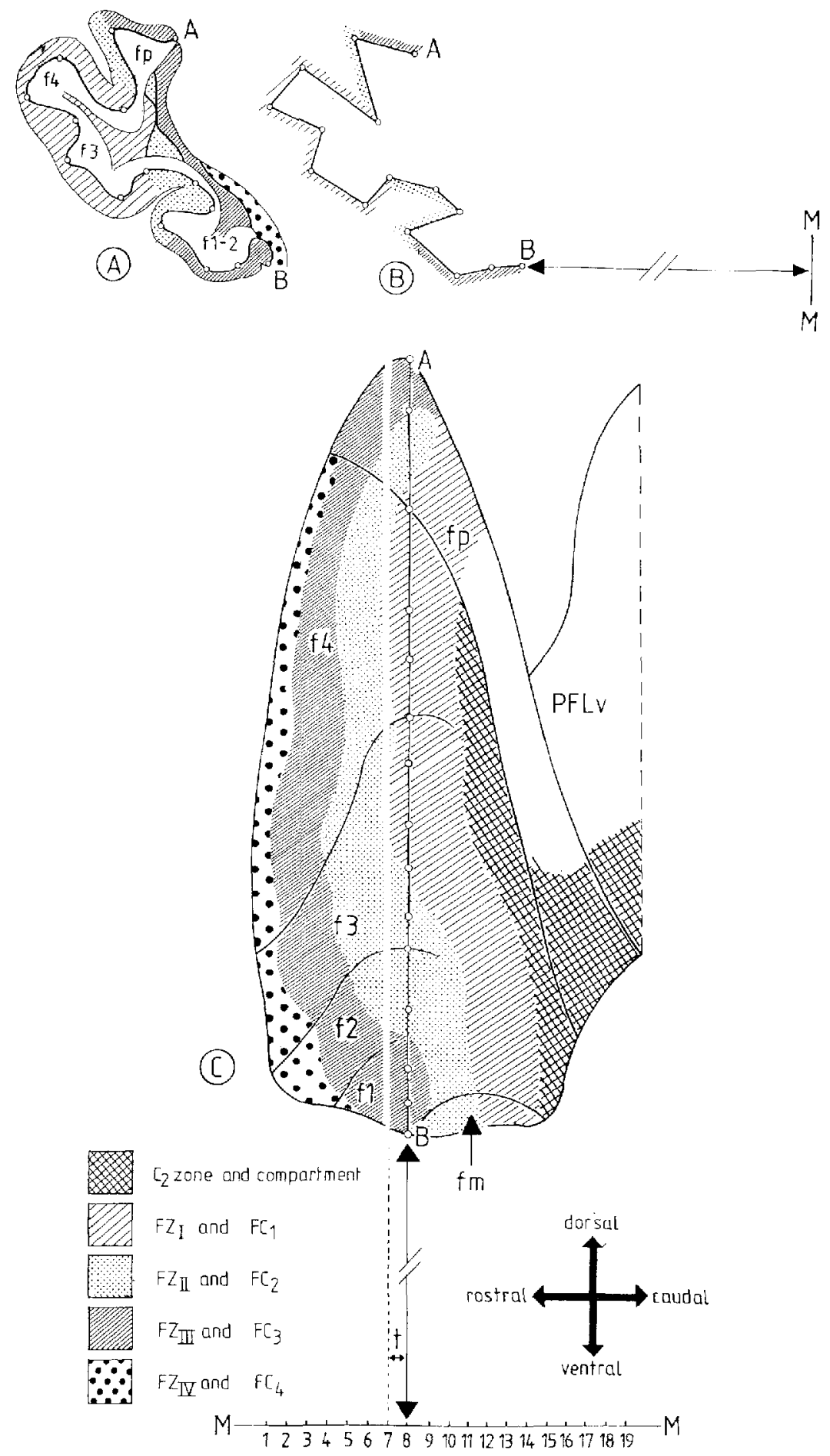

Fig. 1. Diagram of the method used to unfold the cortex in preparing maps of the flocculus to show the approximate extent of the floccular zones. A: The extent of the zones was estimated by extrapolating the acetylcholinesterase ( $\mathrm{AChE}$ ) positive raphes to the Purkinje cell layer. B: The Purkinje cell layer A-B was straightened and the approximate positions of the cortical zones $\mathrm{FZ}_{\text {IV }}$ and $\mathrm{C}_{2}$ were indicated. Sections were aligned using the distance between the midline (M) and the most ventromedial point of the Purkinje cell layer (point B). C: The position of section 8 illustrated in $\mathrm{A}$ and $\mathrm{B}$ is indicated on the reconstructed map of the flocculus and folium $p$. The map is positioned as if viewed from the lateral side. The distance between the reconstructed sections ( $t$ ) was obtained by multiplying the true distance between the sections by the magnification factor, and therefore the rostrocaudal scale is the same as the dorsoventral scale. Symbols indicating floccular zones and compartments are explained in the lower left panel.

according to the extent and location of the injection sites in the flocculus compared with the estimated position of the FZ bands.

Group 1: Injections of zone $F Z_{1}(K 244, K 355, K 358$, and $K \mathbf{3 6 0}$ ). In this group, small injections of WGA-HRP in the cortex of the flocculus resulted in labeled fibers that were clearly grouped in compartment $\mathrm{FC}_{1}$ (Figs. 7A,B, 9). The injection sites in $\mathrm{K} 244$ and $\mathrm{K} 355$ are situated within the estimated borders of $\mathrm{FZ}_{\mathrm{I}}$ (Fig. 8C,D), and the injections in $\mathrm{K}$ 358 and $\mathrm{K} 360$ encroach upon $\mathrm{FZ}_{\mathrm{II}}$ (Figs. 6C, $8 \mathrm{E}$ ).
The injection site in $\mathrm{K} 244$ is located in $\mathrm{f} 3-4$ and extends more caudally than in the other three cases (Figs. 8C, 9C). The labeled fibers are located in the lateral half of compartment $\mathrm{FC}_{1}$. No labeled fibers were present in any of the other compartments. Labeled neurons in the inferior olive are almost restricted to the vlo and the rdc (Fig. 14). In the caudal flocculus fibers in this compartment pass medially, dorsal to compartment $\mathrm{FC}_{2}$, where they subdivide into two fiber streams. One stream curves dorsalward through the lateral cerebellar nucleus, turning medially and caudally 

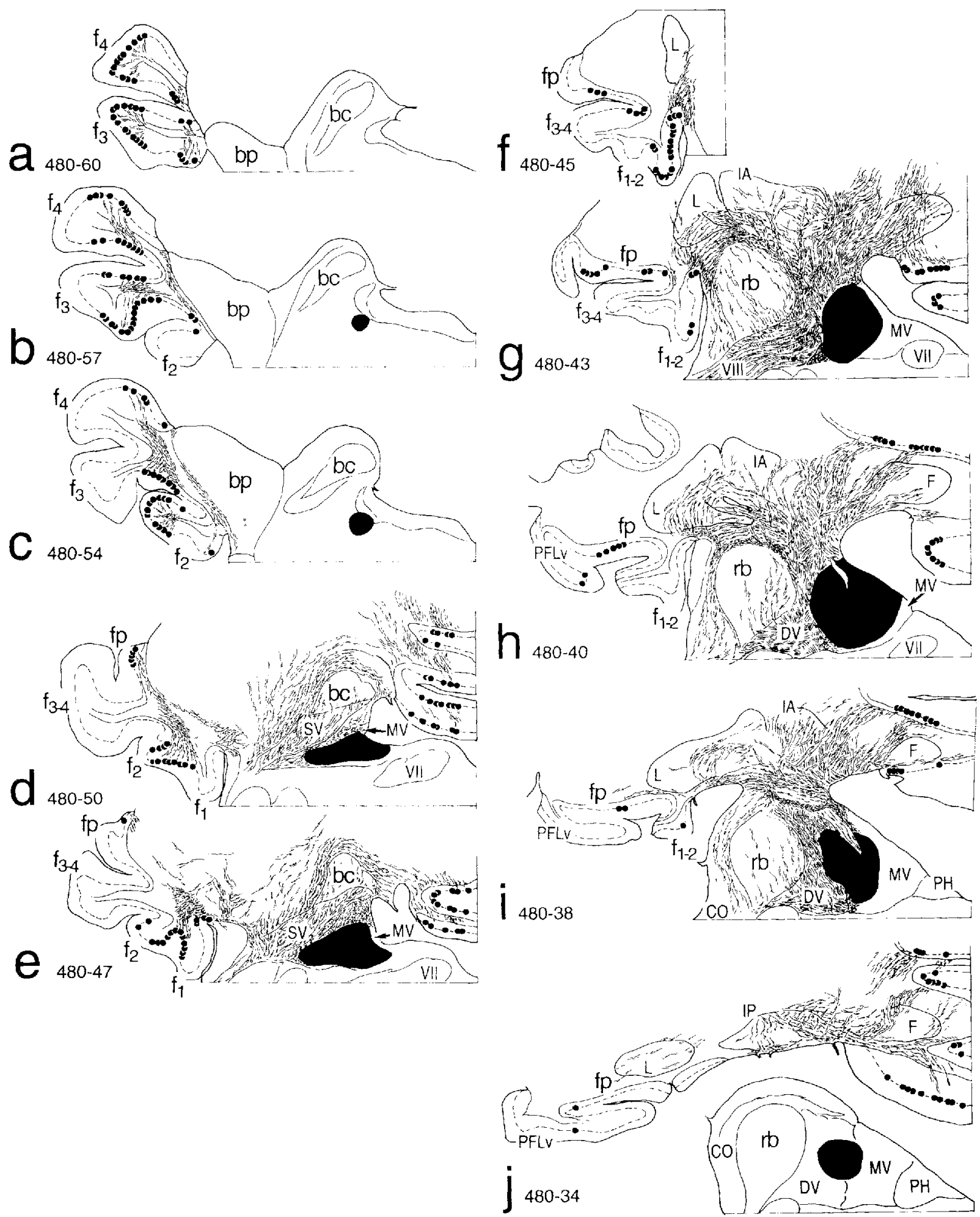

Fig. 2, a-j: Drawings of retrogradely labeled Purkinje cells and their axons in transverse sections through the flocculus and floccular peduncle of case $\mathrm{C} 480$ with a horseradish peroxidase (HRP) injection

site (black) involving the rostral part of the medial vestibular nucleus. Most Purkinje cell axons occupy compartments $\mathrm{FC}_{2}$ and $\mathrm{FC}_{4}$, with labeled cells in the corresponding zones $\mathrm{FZ}_{[l}$ and $\mathrm{FZ}_{\mathrm{IV}}$.

along the dorsal border and through the parvicellular lateral cerebellar nucleus. Within the anterior interposed nucleus they turn abruptly ventrally to enter the caudal lateral vestibular nucleus (LV) and the DV, close to the restiform body. No clear signs of termination of these fibers were observed in the cerebellar nuclei. The second stream pole of the SV (Fig. 9e,f). A few fibers continue along the remains in a ventral position and enters the floccular 


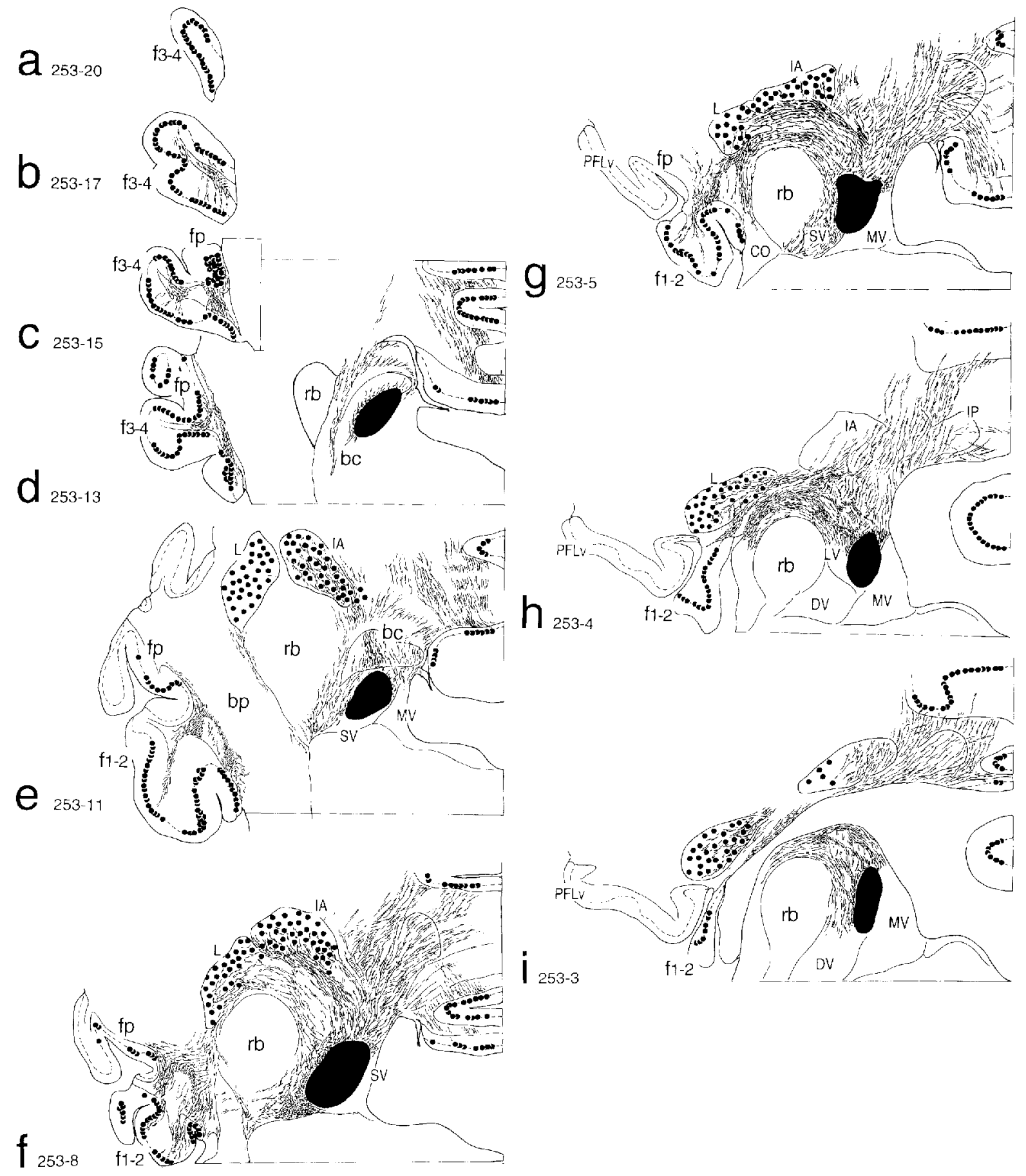

Fig. 3. a-i: Drawings of retrogradely labeled Purkinje cells and their axons in transverse sections through the flocculus and floccular peduncle of $C 253$ with an HRP injection site (black) involving the superior vestibular nucleus. Most Purkinje cell axons occupy compart-

ments $\mathrm{FC}_{1}$ and $\mathrm{FC}_{3}$, with labeled neurons in zones $\mathrm{FZ}_{\mathrm{I}}$ and $\mathrm{FZ}_{\mathrm{IIT}}$. An extension of the injection site, involving the superior cerebellar peduncle (d), causes retrograde labeling of many ncurons in the cerebellar nuclei $(e-i)$.

peduncle. It comprises the bulk of the fibers of compartment $\mathrm{FC}_{1}$. Labeled fibers ramify among the cells of dorsal group $\mathrm{y}$ situated between the fibers of the floccular peduncle (Figs. 9f, 10B,C). Due to the great number of labeled fibers traversing through dorsal group $y$ it cannot be established with certainty whether the axons actually terminate on these neurons. Labeled fibers are scarce in

ventral and dorsal parts of the floccular peduncle. A few labeled fibers pass through ventral group y, along the dorsal border of the restiform body. Very few fibers passing through the caudal pole of SV enter Löwy's bundle. Labeled fibers of the second stream intersect with fibers arching through the lateral and interposed nuclei in the region of the caudal pole of SV. Most labeled fibers terminate mainly 


\section{FLOCCULOVESTIBULAR PROJECTIONS}
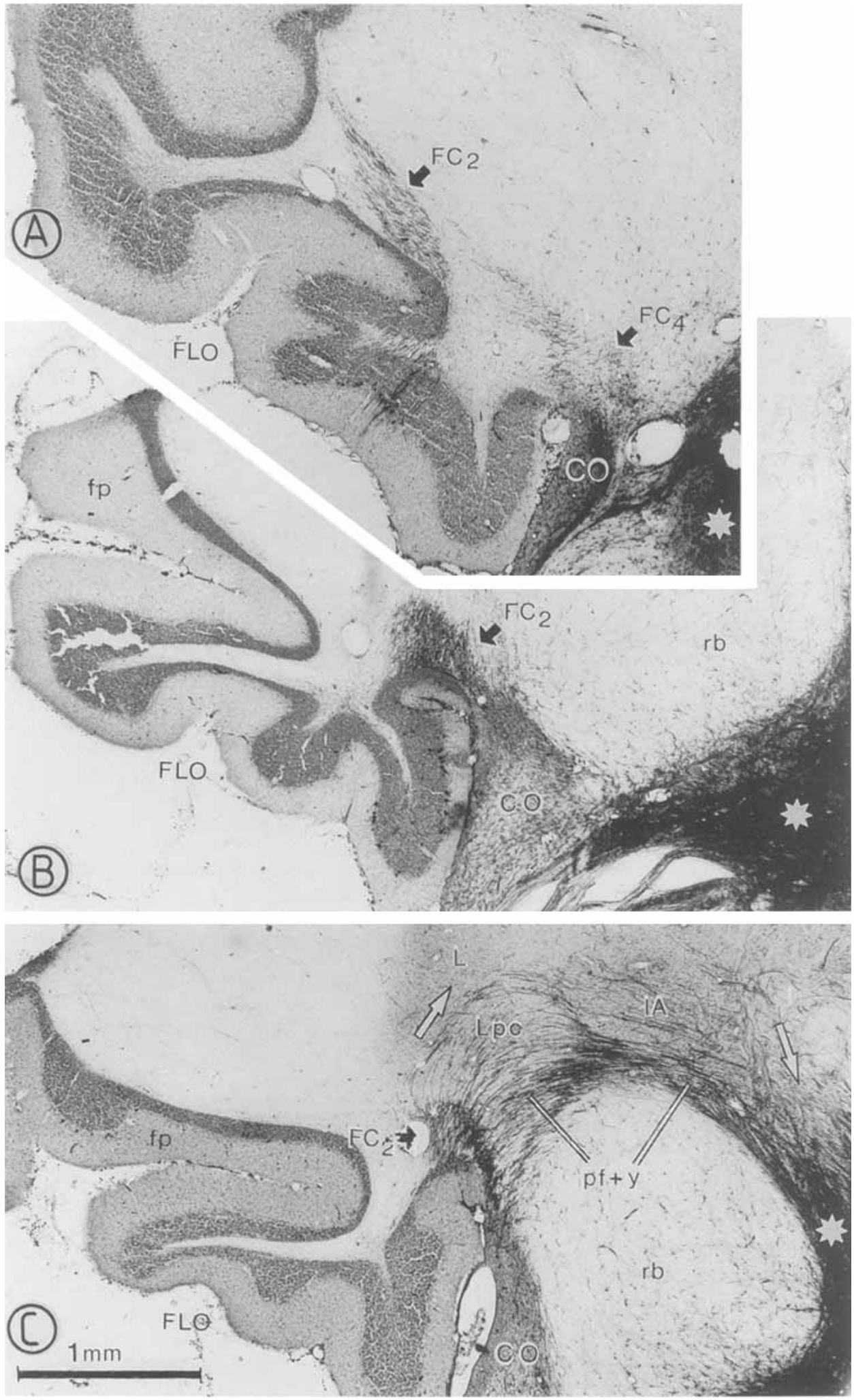

Fig. 4. A-C: Brightfield photomicrographs af transverse sections through the flocculus in C 480 . Compare with Figure 2d, e, and g. White star indicates injection site. White arrows indicate labeled fibors passing through the cerebellar nuclei. 


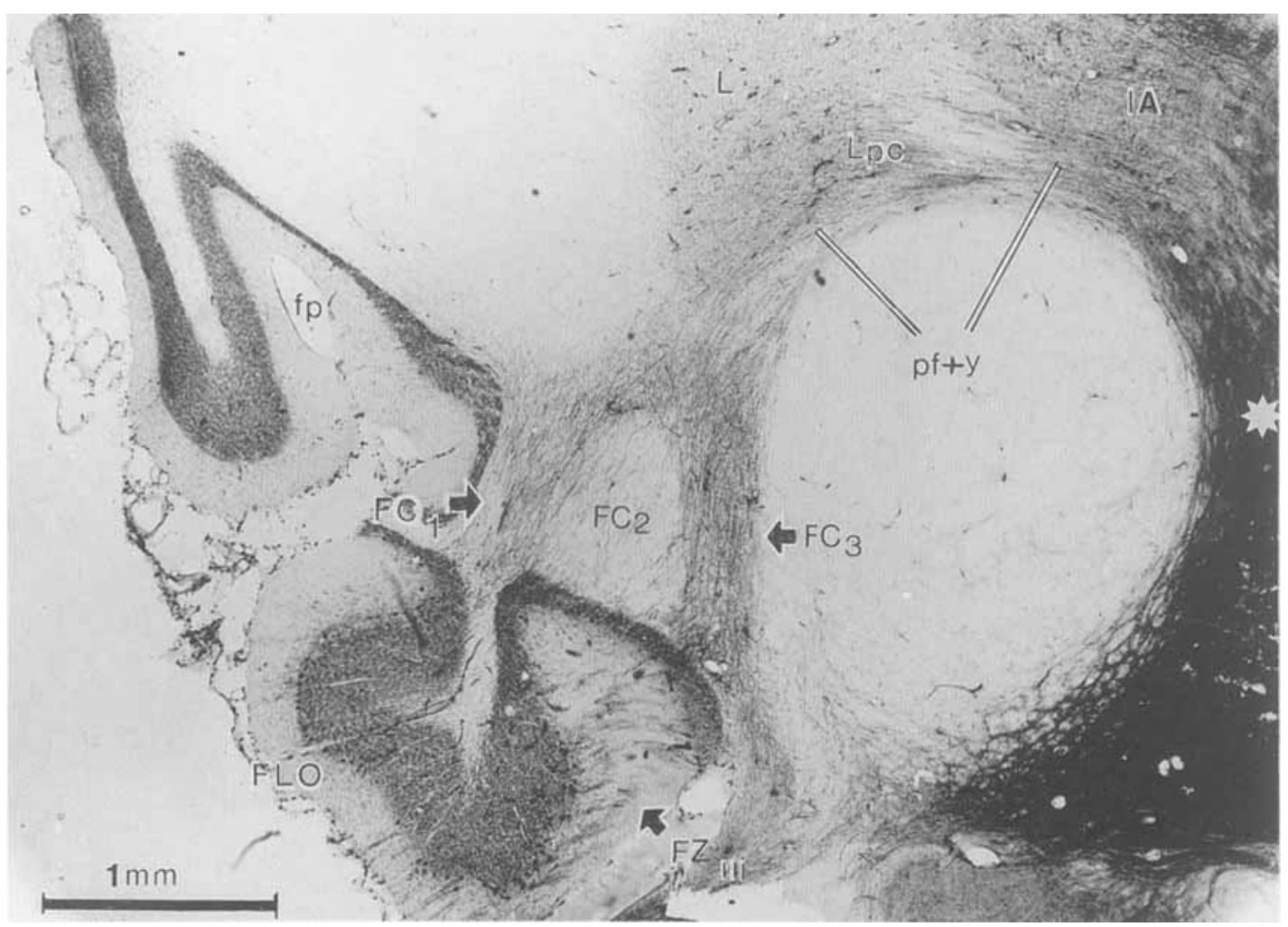

Fig. 5. Brightfield photomicrograph of transverse section through the flocculus in C 253. Compare with Figure 3g. White star indicates injection site.

in the dorsolateral and central parts of SV and in its caudal pole (Fig. 9b-e). A few can be traced into MV and DV. Retrogradely labeled cells of different sizes are bilaterally present in the SV, the MV, and the nucleus prepositus hypoglossi $(\mathrm{PH})$. Some retrogradely labeled cells are present caudally in the ipsilateral dorsal group $y$ and in the region caudal and dorsal to the parvicellular lateral cerebellar nucleus. Small, retrogradely labeled cells extend into the roof of the fourth ventricle to the lateral border of the nodulus. A few labeled neurons are present in the contralateral group y and the parvicellular lateral cerebellar nucleus.

Similar observations were made in K 355 with an injection site located in $\mathrm{f} 3$ in the center of the estimated $\mathrm{FZ}_{\mathrm{I}}$ zone (Fig. 8D). The majority of the retrogradely labeled cells in the inferior olive are located in the vlo and rdc (Fig. 14). Labeled fibers in the cerebellar white matter are mainly located in the medial half of compartment $\mathrm{FC}_{1}$ with a few fibers in $\mathrm{FC}_{2}$.

The injection site in $\mathrm{K} 360$ (Fig. $6 \mathrm{C}$ ) is situated in $\mathrm{FZ}_{\mathrm{I}}$, but encroaches upon $\mathrm{FZ}_{\mathrm{II}}$. Labeled fibers in $\mathrm{K} 360$ (Fig. 7A,B) and $\mathrm{K} 358$ are located in $\mathrm{FC}_{1}$ and some in central $\mathrm{FC}_{2}$. The majority of the retrogradely labeled cells in the olive in these cases are located in the vlo and rdc, but a substantial number are found in the cdc. The localization of the injection sites in these two cases in $\mathrm{FZ}_{\mathrm{I}}$ with encroachment upon $\mathrm{FZ}_{\Pi \mathrm{II}}$ (Figs. 6C, 8E) is compatible with the projection of the rostral de/vlo and the caudal de to $\mathrm{FZ}_{1}$ and $\mathrm{FZ}_{\mathrm{T}}$, respectively (Tan et al., 1995b) and the relations of these Purkinje cell zones to their white matter compartments, as established in previous experiments. Labeled fibers could be traced through the floccular peduncle and the lateral and interposed nuclei to be distributed to dorsolateral, central, and caudal parts of the SV and DV, to the region of the MV bordering on the dorsal acoustic stria, and to more caudal parts of this nucleus. Diffuse labeling was present in the medial part of the cochlear nucleus.

Group 2: Injections of zone $F Z_{I}(K 301, K 305$, and $K 340)$. In these injections the labeled Purkinje cell axons travel in compartment $\mathrm{FC}_{2}$. In cases $\mathrm{K} 301$ and $K 340$ retrograde labeling in the contralateral inferior olive prevails in the cdc (Fig. 14). The caudal pole of the inferior olive in $\mathrm{K} 305$ was not sectioned, but no labeled cells were present in the vlo.

The injection site in $\mathrm{K} 305$ is located in the $\mathrm{FZ}_{\mathrm{II}}$ zone of $\mathrm{f} 2$ (Figs. 6B, 11C). The labeled fibers occupy most of compartment $\mathrm{FC}_{2}$ except for a dorsal triangle (Fig. 11c-e). This triangle became filled after the injection of $F Z_{I I}$ in folium $p$ in case K 301 (Fig. 7C). A few labeled fibers are present in $\mathrm{FC}_{3}$. At the level of the floccular peduncle the fibers follow a course similar to that of fibers in the previous experiments. Two fiber streams can be observed. A small number of fibers curve through the lateral cerebellar and anterior interposed nuclei but there are no clear signs of termination of these fibers in the cerebellar nuclei. These fibers subsequently enter the vestibular nuclei through the caudal SV, lateral to LV. The majority of the fibers accumulate in the floccular peduncle and travel medially in Löwy's bundle to the lateral angle of the fourth ventricle where they bend sharply in a ventral direction to enter MV. Labeled fibers in the floccular peduncle traverse the dorsal and ventral divisions of group $y$, but no distinct signs of termination could be observed. The majority of the labeled fibers terminate in MV. They are present in the rostral MV 
Fig. 6. A-C: Maps of the flocculus and folium p showing the extent of injection sites (black) and their approximate position in relation to the floccular zones. The maps are reconstructed from transverse serial sections of $\mathrm{K} 301, \mathrm{~K} 305$, and $\mathrm{K}$ 360 . One transverse section containing the injection site is illustrated for each experiment; the position of this section is indicated by a vertical line. For explanation of the symbols indicating zones and compartments, see Figure 1 . The scale bar applies to all panels, and the rostrocaudal scale is the same as the dorsoventral scale.
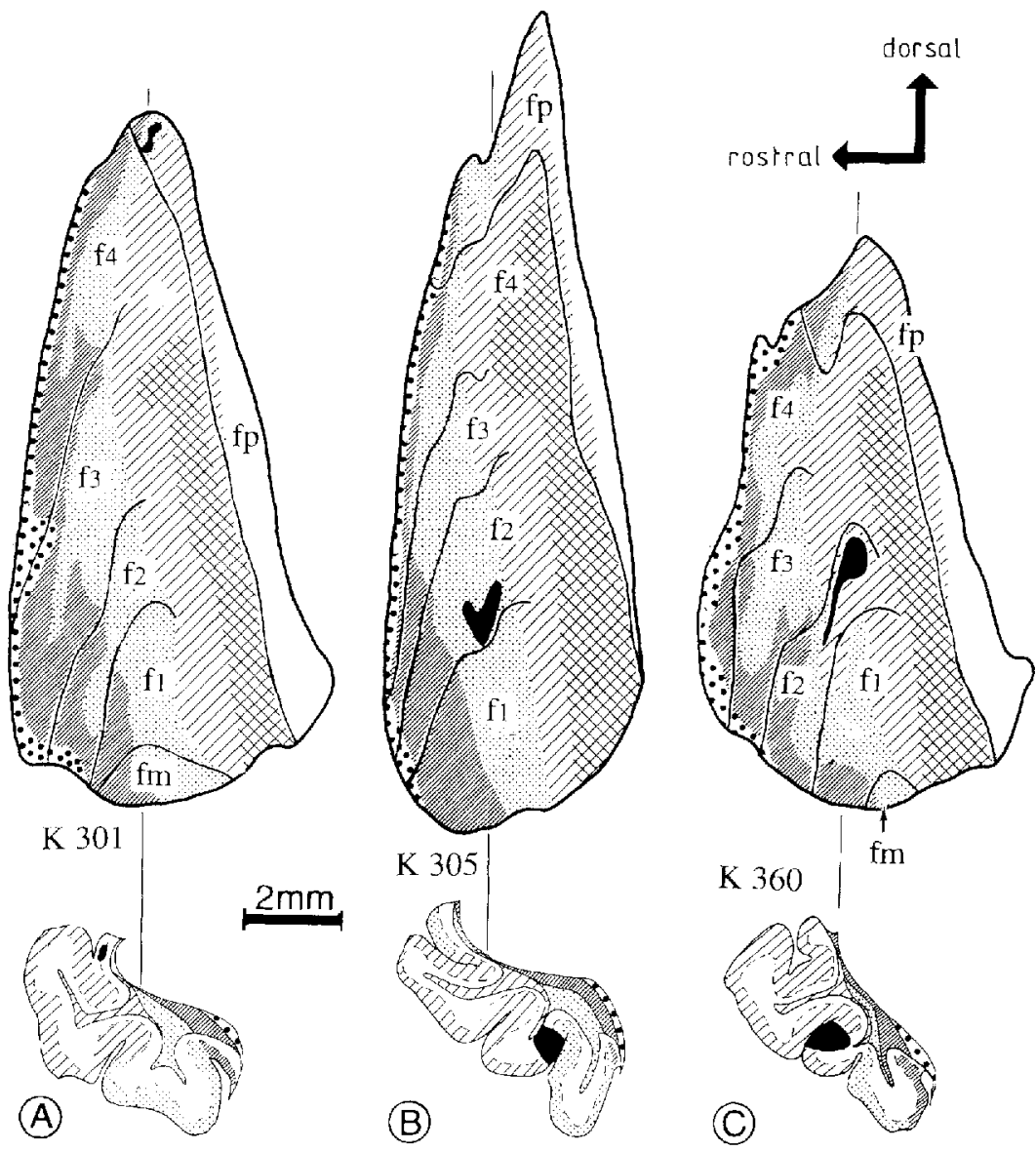

(C)

caudal parts of the SV (Fig. 13A,B). A few fibers travel through Löwy's bundle, and through DV, toward MV, where they terminate in the region surrounding the acoustic stria and in more caudal parts of this nucleus. A considerable number of labeled fibers appear to terminate in the dorsal cochlear nucleus (Fig. 12g-i). A few labeled fibers were seen in the PH. Retrogradely labeled cells are present bilaterally in the SV, DV, and MV. The ipsilateral dorsal group y contains some retrogradely labeled cells, and a few are present in ventral group y; more labeling is observed around and caudal to the parvicellular lateral nucleus. A few labeled cells are present in contralateral group y. Small labeled neurons in the roof of the fourth ventricle extend ventral to the cerebellar nuclei, into the white matter of the nodulus (Fig. 12h). Labeling in case K 227 is a combination of the distributions in groups 2 and 3 . Fibers terminate in the SV, MV, and DV.

\section{Conclusions}

Retrograde labeling of Purkinje cells from HRP injections in their target nuclei confirmed the localization of MV. projecting cells in two zones that interdigitate with two other zones projecting to the SV (Yamamoto and Shimoyama, 1977). The most rostral zone projects to the MV. The axons of these Purkinje cells collect in four bundles that correspond to the white matter compartments $\mathrm{FC}_{1-4}$, delineated in previous studies (Tan et al., 1995a). Anterograde WGA-HRP tracing combined with AChE histochem- 

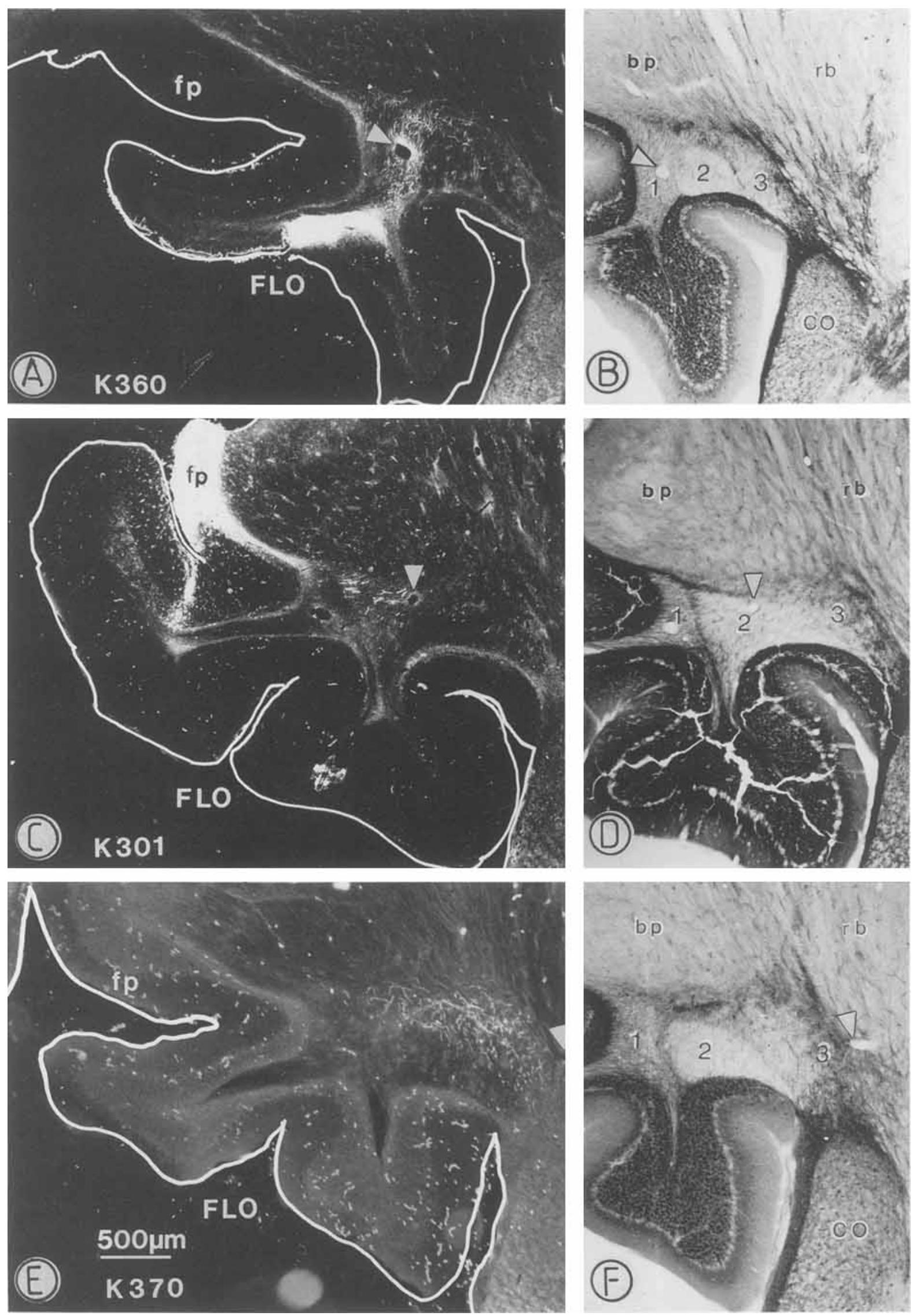

Fig. 7. Darkfield and brightfield photomicrographs of tetramethyl benzidine (TMB)-processed (A,C,E) and adjoining AChE-processed $(B, D, F)$ sections through the flocculus showing the position of labeled fibers in the different white matter compartments. A, B: K 360 with an injection site in $\mathrm{FZ}_{\mathrm{I}}$ and anterogradely labeled fibers in $\mathrm{FC}_{1}$. C, D: K 301 with an injection site in $\mathrm{FZ}_{\mathrm{T}}$ and labeled fibers in $\mathrm{FC}_{2}$. $\mathbf{E}, \mathbf{F}: \mathrm{K} 370$ with an injection site in $\mathrm{F}_{1 \mathrm{II}}$ (see Fig. 8A) and labeled fibers in $\mathrm{FC}_{3}$. White arrowheads indicate position of blood vessels to facilitate the comparison of the darkficld and $\mathrm{AChE}$-stained sections; 1-3 indicate compartments $\mathrm{FC}_{1-3}$. The scale bar in $\mathrm{E}$ also applies to the other panels. 
istry demonstrated that Purkinje cells of the floccular zones project to specific parts of the vestibular complex (Fig. 15). $\mathrm{FZ}_{\mathrm{I}}$ and $\mathrm{FZ}$ mainly project to dorsolateral, central, and caudal parts of the SV with possible minor projections to the DV, MV, and $\mathrm{PH} . \mathrm{FZ}_{\mathrm{II}}$ and $\mathrm{FZ}_{\mathrm{IV}}$ project to the $\mathrm{MV}$ with possible minor projections from $\mathrm{FZ}_{\mathrm{II}}$ to the $\mathrm{SV}$ and $\mathrm{PH}$. The possible minor projections to the SV and MV are likely due to spread of the tracer to neighboring Purkinje cell zones. Terminations were consistently found in the MV region surrounding the dorsal acoustic stria. Most labeled fibers in the DV seem to pass through this nucleus on their way to the MV rather than to terminate there.

Termination of fibers passing through group y could not be definitely established. Ramifications of labeled fibers around neurons of dorsal group y were observed in cases with injections of $\mathrm{FZ}_{1}$ and $\mathrm{FZ}_{\mathrm{II}}$, but not with injections of the $\mathrm{FZ}_{\mathrm{II}}$ zone. Terminations of arciform fibers from $\mathrm{FZ}_{\mathrm{I}}$ and $\mathrm{FZ}_{\mathrm{II}}$ in the cerebellar nuclei and the Lpc cannot be excluded. No arciform fibers were observed in cases with injections of $\mathrm{FZ}_{\mathrm{III}}$. Fine labeling was observed in the dorsal cochlear nucleus in some cases with injections of $\mathrm{FZ}_{\mathrm{I}-\mathrm{III}}$, but not in all of them. No experiments with small injections of WGA$\mathrm{HRP}$ in $\mathrm{FZ}_{\mathrm{TV}}$ and $\mathrm{C}_{2}$ were available.

\section{DISCUSSION}

The present study shows that the Purkinje cells of the flocculus are partitioned in zones. Purkinje cell axons of each zone collect in a white matter compartment and project to specific parts of the vestibular nuclear complex. The data on pathways of Purkinje cell axons demonstrated with anterograde tracing with WGA-HRP are supported by the findings in our retrograde HRP experiments.

\section{The retrograde and anterograde axonal tracing methods used in this study}

Two methods have been used in this study to trace the efferent pathways and connections of the flocculus: retrograde axonal transport of HRP injected in the vestibular nuclei and anterograde axonal transport of WGA-HRP injected in the flocculus.

Retrograde filling with HRP of Purkinje cells and their axons, demonstrated with $\mathrm{DAB}$ as a substrate, has been used before to map the corticonuclear and corticovestibular projections (Voogd and Bigaré, 1980; Voogd, 1989; Voogd et al., 1987). Anterograde transport in vestibulo-cerebellar mossy fibers, which would have hindered the identification of labeled axons as belonging to the retrogradely labeled Purkinje cells, was never observed in the previous or in the present experiments. WGA-HRP demonstrated with TMB is a more sensitive method. Moreover, WGA-HRP is transported both anterogradely and retrogradely (Lechan et al., 1981; Trojanowski et al., 1981). The injections with very small amounts of WGA-HRP in the cortex of the flocculus, used for anterograde tracing of the Purkinje cell axons, also caused retrograde labeling of neurons bilaterally in the vestibular nuclei and in the contralateral inferior olive. This raises the question of whether some of the axonal labeling observed in our experiments could have been due to retrograde transport in the axons of these labeled cells. This is unlikely because few, if any, axons of these cells were retrogradely labeled in these cases. Labeled olivocerebellar axons were not observed in the olivary decussation or the restiform body, and no labeled fibers could be traced from labeled cells in the contralateral vestibular nuclei to the flocculus. Moreover, the distribution of labeled Purkinje cell axons in the ipsilateral vestibular nuclei varies systematically with the localization of the injection site, whereas the distribution of retrogradely labeled cells in the vestibular nuclei remained roughly the same in all experiments (see Sato et al., 1983; Magras and Voogd, 1985; and Thunnissen, 1990 for other experiments showing lack of zonal differentiation in terminations of secondary vestibulocerebellar mossy fibers). Anterograde transport of WGAHRP can, therefore, be used to study the distribution of Purkinje cell axons.

\section{Zonal organization of Purkinje cells projecting to the medial and superior vestibular nuclei and group y}

The overall distribution of the floccular Purkinje cell axons is similar to earlier reports on the rabbit (Epema, 1990) and other species (Voogd, 1964; Angaut and Brodal, 1967, cat; Haines, 1977, Galago; Langer et al., 1985, macaque monkey). Epema (1990) noticed the two routes followed by these fibers. One runs ventrally through the floccular peduncle, between the Lpc and the restiform body. Some of its fibers proceed, dorsal to the LV, to Löwy's bundle near the lateral corner of the fourth ventricle. The second route consists of arciform fibers curving dorsally and caudally through the lateral cerebellar and the anterior interposed nuclei. Medial to the Lpc and lateral to the $\mathrm{LV}$ they rejoin the fibers of the floccular peduncle. Arciform fibers passing through the lateral cerebellar nucleus were also observed in cat and Galago, but not in macaque monkey (Langer et al., 1985).

Judging from the localization of the injection sites, the distribution of the labeled Purkinje cell axons over the white matter compartments, and the retrograde labeling in the inferior olive, most of the injections of WGA-HRP in the cerebellar cortex were focused on a single floccular zone, although encroachment into neighboring zones did occur in some experiments. With respect to the zonal organization of the projections from the flocculus, our experiments with retrograde labeling of HRP show that Purkinje cell axons of $\mathrm{FZ}_{\mathrm{TI}}$ and $\mathrm{FZ}_{\mathrm{TV}}$, contained in compartments $\mathrm{FC}_{2}$ and $\mathrm{FC}_{4}$, project to the $\mathrm{MV}$, whereas those from $\mathrm{FZ}_{\mathrm{I}}$ and $\mathrm{FZ}_{\mathrm{III}}$, located in $\mathrm{FC}_{1}$ and $\mathrm{FC}_{3}$, project to the $\mathrm{SV}$. These experiments confirm and extend the observations of Yamamoto and Shimoyana (1977) in the rabbit, especially with respect to the presence of a medial $\mathrm{FZ}_{\mathrm{IV}}$ zone and a corresponding $\mathrm{FC}_{4}$ compartment projecting to the MV. Fibers from $\mathrm{FZ}_{T}$ and $\mathrm{FZ}_{11}$ travel along both the ventral route through the floccular peduncle and dorsal group y, and the dorsal route, curving through the lateral and anterior interposed cerebellar nuclei and the Lpc. Fibers from $\mathrm{FZ}_{\mathrm{II}}$ pass exclusively through the floccular peduncle. Within the vestibular nuclei labeled fibers avoid the lateral vestibular nucleus. On their way to the MV they either pass lateral to the LV and through the DV, or through Löwy's bundle.

Terminations in regions traversed by labeled fibers (such as group $y$, the Lpc, the lateral and anterior interposed cerebellar nuclei, and the DV) were difficult to establish with certainty. In cases with injections of $\mathrm{FZ}_{\mathrm{I}}$ and $\mathrm{FZ}_{\mathrm{III}}$ labeled fibers ramified among the cells of dorsal group $y$, but no such ramifications were seen with injections of $\mathrm{FZ}_{\mathrm{II}}$. A few labeled fibers extend into PH in cases with injections of $\mathrm{FZ}_{\mathrm{II}}$ and $\mathrm{FZ}_{\mathrm{III}}$. Projections to the dorsal cochlear nucleus, previously found by Epema (1990), were observed in some, but not all experiments with injections of $\mathrm{FZ}_{\mathrm{I}-11 !}$. Our 

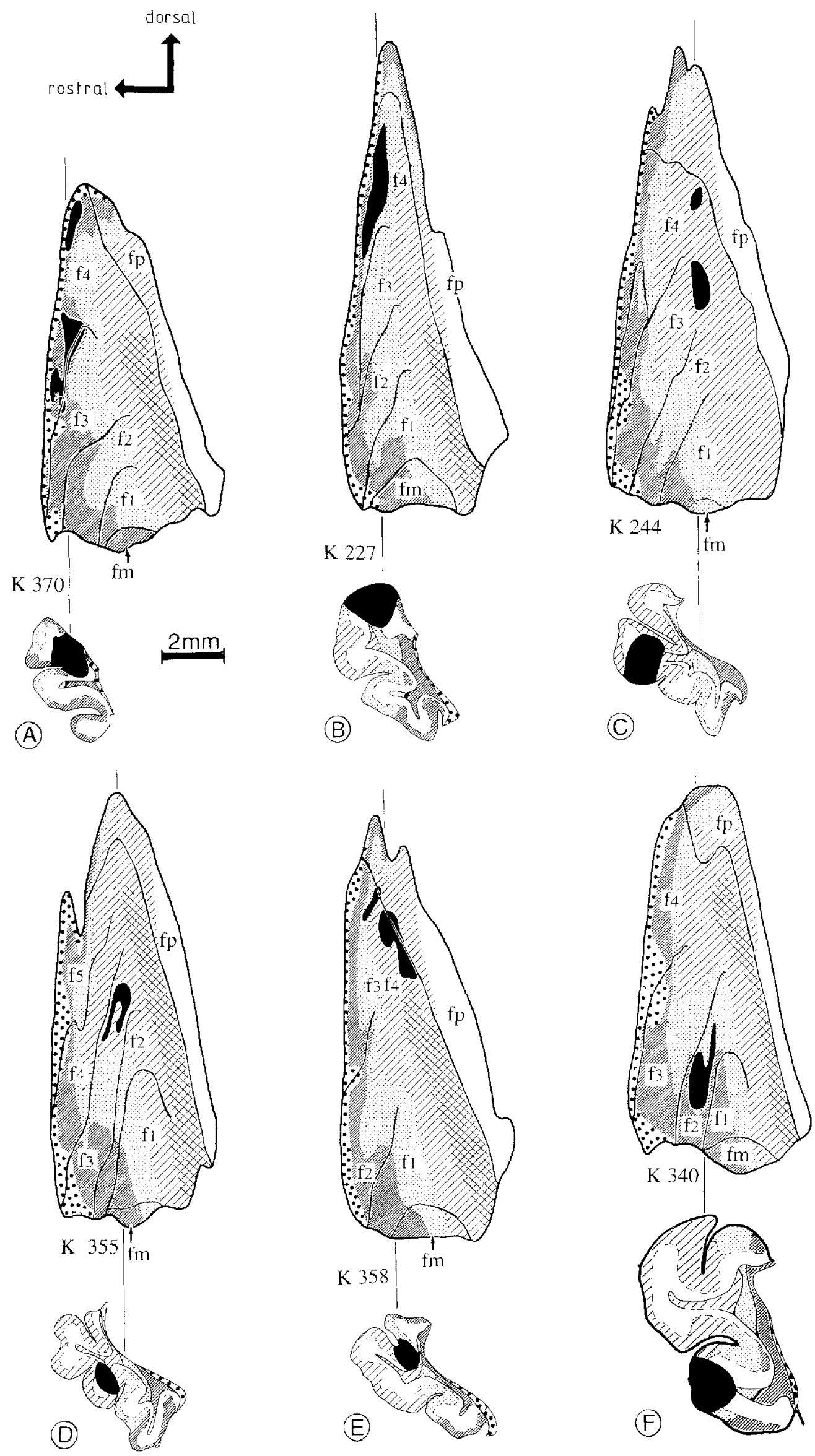
observations are in accordance with the results of De Zeeuw et al. $(1992,1994 \mathrm{~b})$, who traced axons from individual Purkinje cells of the rabbit flocculus with biocytin. They found projections from Purkinje cells of $\mathrm{FZ}_{\mathrm{I}}$ and $\mathrm{FZ}$ III to the $\mathrm{SV}$, and from $\mathrm{FZ}_{\mathrm{II}}$ to the parvicellular and magnocellular parts of MV. In addition, they observed terminals from FZ and $\mathrm{FZ}_{\mathrm{IIT}}$ Purkinje cell axons in group $\mathrm{y}$, and for $\mathrm{FZ}_{\mathrm{I}}$ also in the Lpc. $\mathrm{FZ}_{\mathrm{II}}$ did not project to group $\mathrm{y}$ or the lateral cerebellar nucleus.

Our findings are in fair agreement with the studies of Yamamoto (1978), Balaban et al. (1981), and Sato et al. (1982a,b). Our zones $\mathrm{FZ}_{11}$ and $\mathrm{FZ}_{\mathrm{III}}$ correspond to the middle and rostral zones of the flocculus of the cat (Sato et al., 1982a) and the monkey (Balaban et al., 1981), which also project to the MV and SV, respectively. By the absence of a projection to SV, the caudal zone of the cat flocculus differs from the $\mathrm{FZ}_{\top}$ zone of the rabbit (Sato et al., 1982b). It is still possible that zones equivalent to $\mathrm{FZ}_{\mathrm{I}}$ and $\mathrm{C}_{2}$ exist in the caudal cat flocculus, and that the injections of the lateral cerebellar nucleus and group y labeled fibers of passage of $\mathrm{FZ}_{\mathrm{I}}$ and $\mathrm{C}_{2}$ on their way to the $\mathrm{SV}$ and the posterior interposed nucleus, respectively. A caudal zone that projects to the $\mathrm{SV}$ and corresponds to $\mathrm{FZ}_{\mathrm{I}}$ was found in the monkey (Balaban et al., 1981).

\section{Correspondence of corticovestibular zones with climbing fiber zones in the rabbit flocculus}

The zonal pattern described in the present study corresponds well with the zonation of climbing fibers demonstrated with anterograde WGA-HRP tracing in rabbit (Tan et al., 1995b) and Phaseolus vulgaris-leucoagglutin transport in the rat (Ruigrok et al., 1992) and the autoradiographic study of Gerrits and Voogd (1982) in the cat. In a previous paper, we compared the climbing fiber projection to the flocculus with the compartmentation in adjacent AChE-stained sections as a reference (Tan et al., 1995b). We found close correlations between particular subsets of olivary neurons and certain white matter compartments. The cdc projected through compartments $\mathrm{FC}_{2}$ and $\mathrm{FC}_{4}$ to floccular zones $\mathrm{FZ}_{\mathrm{II}}$ and $\mathrm{FZ}_{\mathrm{IV}}$, while rdc/vlo neurons projected through compartments $\mathrm{FC}_{1}$ and $\mathrm{FC}_{3}$ to $\mathrm{FZ}_{\mathrm{I}}$ and $\mathrm{FZ}_{\mathrm{III}}$. Our observations on retrograde labeling of cells of the dorsal cap and the ventrolateral outgrowth in experiments with small injections of individual floccular zones generally support this conclusion (Fig. 14).

\section{Functional considerations}

The vestibular nuclei contain excitatory and inhibitory relay neurons for the vestibulo-ocular reflexes that convey input from the semicircular canals (Ito et al., 1973). Purkinje cells of the flocculus innervate horizontal and anterior canal relay cells, but they do not terminate on relay cells of the posterior canal (Ito et al., 1973, 1977, 1982a,b).

Fig. 8. A-F: Maps of the flocculus and folium p, showing the extent of injection sites (black) and their approximate position in relation to the foccular zones. The maps are reconstructed from transverse serial sections of $\mathrm{K} 370, \mathrm{~K} 227, \mathrm{~K} 244, \mathrm{~K} 355, \mathrm{~K} 358$, and $\mathrm{K} 340$. One transverse section containing the injection site is illustrated for each experiment; the position of this section is indicated by a vertical line. For explanation of the symbols indicating zones and compartments see Figure 1. The scale bar applies to all panels, and the rostrocaudal scale is the same as the dorsoventral scale.
Fibers from $\mathrm{FZ}_{\mathrm{I}}$ and $\mathrm{FZ}_{\text {III }}$ terminate mainly in the dorsolateral, central, and caudal parts of the SV and in dorsal group y (De Zeeuw et al., 1992, 1994b; this paper). Inhibitory anterior canal relay cells that innervate inferior rectus and superior oblique motoneurons of the ipsilateral oculomotor and trochlear nuclei through the medial longitudinal fascicle occupy the central part of the SV. Excitatory anterior canal relay cells that project through the brachium conjunctivum $^{1}$ to contralateral motoneurons innervating the superior rectus and the inferior oblique muscles are located in the dorsolateral SV. (Highstein, 1973; Ito et al., 1977; Yamamoto et al., 1978; Highstein and Reisine, 1979; Hirai and Uchino, 1984; Sato and Kawasaki, 1990b; LabandeiraGarcia et al., 1991). Excitatory neurons with projections through the brachium conjunctivum to the contralateral IIId nucleus are also present in dorsal group y (Highstein, 1971, 1973; Graybiel and Hartwieg, 1974; Hwang and Poon, 1975; Highstein and Reisine, 1979; Stanton, 1980; Carpenter and Cowie, 1985; Sato and Kawasaki, 1987; Labandeira-Garcia et al., 1991). Experiments in the cat showed that dorsal group y cells differ from the anterior canal relay cells in the SV because the former receive an excitatory polysynaptic nerve VIII input, presumably from the saccular nerve (Hwang and Poon, 1975; Sato and Kawasaki, 1987). According to Sato et al. (1982a,b, 1984) and Sato and Kawasaki (1987, 1990b), floceular target cells in dorsal group $\mathrm{y}$ and the SV of the cat receive their input from different Purkinje cell zones. In the rabbit, however, both $\mathrm{FZ}_{\mathrm{I}}$ and $\mathrm{FZ}_{\mathrm{III}}$ project to the $\mathrm{SV}$ and to dorsal group $\mathrm{y}$ (De Zeeuw et al., 1992, 1994b; this paper). Projections to the parvicellular part of the lateral cerebellar nucleus were traced from the caudal zone of the flocculus of the cat (Sato et al., 1982b) and the $\mathrm{F} Z_{\mathrm{I}}$ zone of the rabbit flocculus (De Zeeuw et al, 1992,1994 b). In the rabbit this subnucleus gives rise to a gamma-aminobutyric acid (GABA)ergic projection to the ventrolateral outgrowth and the rostral dorsal cap (De Zeeuw et al., 1994a), which are the sources of the olivocerebellar projection to $\mathrm{FZ}_{\mathrm{I}}$. A projection corresponding to the projection of the primate flocculus to scattered cells located ventral to the dentate and posterior interposed nuclei (basal interstitial nucleus; Langer, 1985) was not observed in the rabbit.

The heaviest projection of $\mathrm{FZ}_{\mathrm{II}}$ is found in the parvicellular MV dorsomedial to the dorsal acoustic stria and among the larger cells of MV ventrolateral to this bundle. Fewer fibers terminate in the most rostral part of $M V$, which is ventral to SV, and in caudal parts of the MV. No fibers were traced to the $L V$ or to the interstitial nucleus of the vestibular nerve. Of the vestibulo-ocular relay cells located in the MV, only horizontal canal cells receive inhibitory projections from the flocculus (Ito et al., 1973, 1977). Kawaguchi (1985) distinguished medial and lateral groups of horizontal canal relay cells that received inhibition from the flocculus in the rabbit. The medial group was located

${ }^{1}$ Hirai and Uchino (1984) and Sato and Kawasaki (1987, 1990b) made a distinction in the cat between the brachium conjunctivum and the pathway [the crossing ventral tegmental tract (CVTT) of Sato and Kawasaki (1987)] followed by the ascending axons of anterior canal relay cells of the dorsal SV and floccular target cells of dorsal group y. These axons collect ventral to the lateral part of the brachium conjunctivum, arch through the lateral tegmentum medial to the lateral lemniscus, and decussate dorsal to the interpeduncular nucleus. This route corresponds to that of the fibers from the ventral part of the dentate nucleus of the cat that are located in the lateral pole of the brachium conjunctivum and decussate in the ventral part of the decussation of the brachium conjunctivum (Voogd, 1964). There is no reason, therefore, to distinguish the CVTT as a separate pathway. 

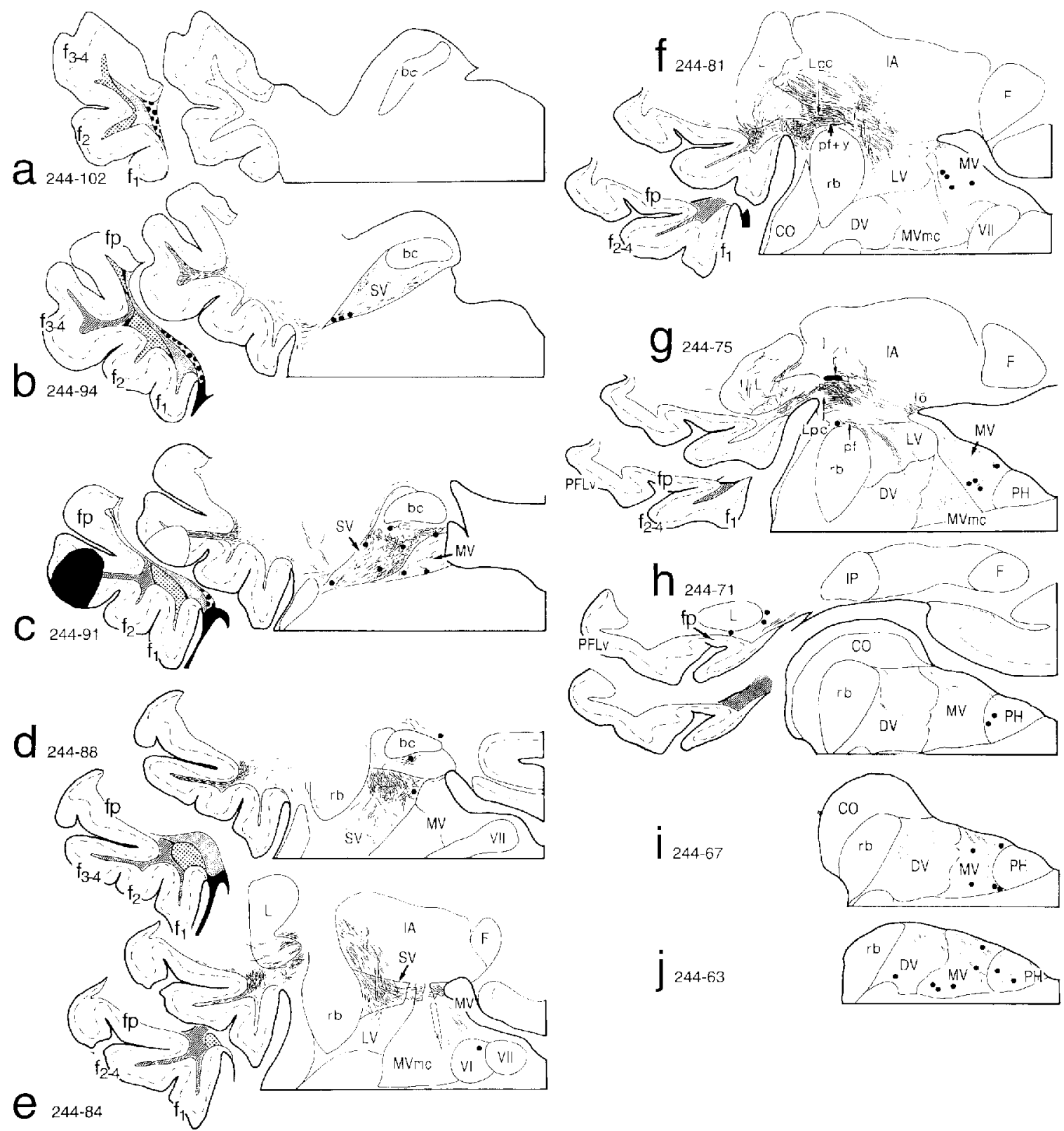

Fig. 9. a-j: Drawings of labeled fibers and neurons in transverse sections through the floceulus and brainstem in case K 244 with an injection in $\mathrm{FZ}_{\mathrm{I}}$. Note the location of efferent fibers in $\mathrm{FC}_{1}$. Fibers follow two routes, one through the floccular peduncle and group $y$ and the

other passing more dorsally through the lateral and anterior interposed cerebellar nuclei. Fibers terminate mainly in the SV. The injection site is indicated in black. Dots represent retrogradely labeled neurons.

medial to the dorsal acoustic stria, and the lateral group was located in the ventrolateral part of the lateral vestibular nucleus (i.e., in the magnocellular part of MV in our terminology). Cells of both groups projected to the ipsilateral medial rectus subdivision of the oculomotor nucleus, but, in addition, the medial group contained cells that, presumably, projected to the ipsilateral abducens nucleus. These latter cells likely correspond to the inhibitory neurons intercalated in the inhibitory vestibulo-ocular pathway to the ipsilateral abducens nucleus (Highstein, 1973; Ito et al., 1977, see also Sato et al., 1988; Sato and Kawasaki, 1991). The projection of the flocculus extends

beyond the dorsal acoustic stria into caudal MV and DV and, therefore, may include neurons with other connections than the oculomotor nuclei (see also Epema, 1990).

The efferent flocculo-vestibular nucleus projection is part of the neuronal circuitry that forms the basis of oculomotor control (Ito et al., 1973). Through these connections Purkinje cells in the flocculus can inhibit the activity of vestibular neurons (Highstein, 1971; Baker et al., 1972; Fukuda et al., 1972; Ito et al., 1977). An imbalance of vestibular discharge activities would result in eye muscle activity. Indeed, local electrical stimulation in the flocculus elicits eye movements (Ron and Robinson, 1973; Dufossé et 


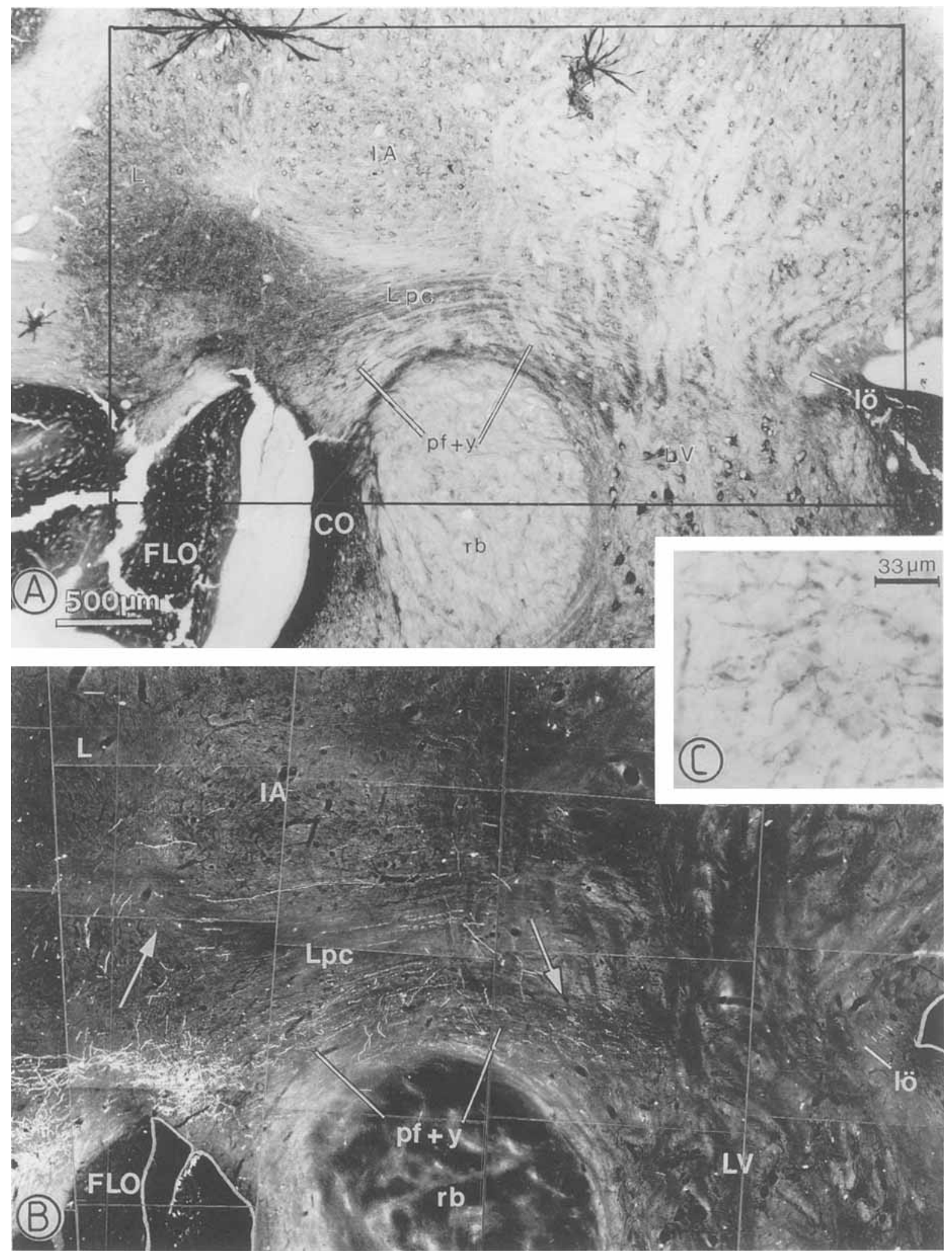

Fig. 10. Brightfield (A,C) and darkfield photographs (B) of the floccular peduncle in K 244. Note the course of the labeled fibers through the floccular peduncle containing the cells of dorsal group y (pf $+\mathrm{y}$ ) and the presence of fibers arching through the cerebellar nuclei (arrows in B). Labeled fibers ramify among the cells of dorsal group y (c). 

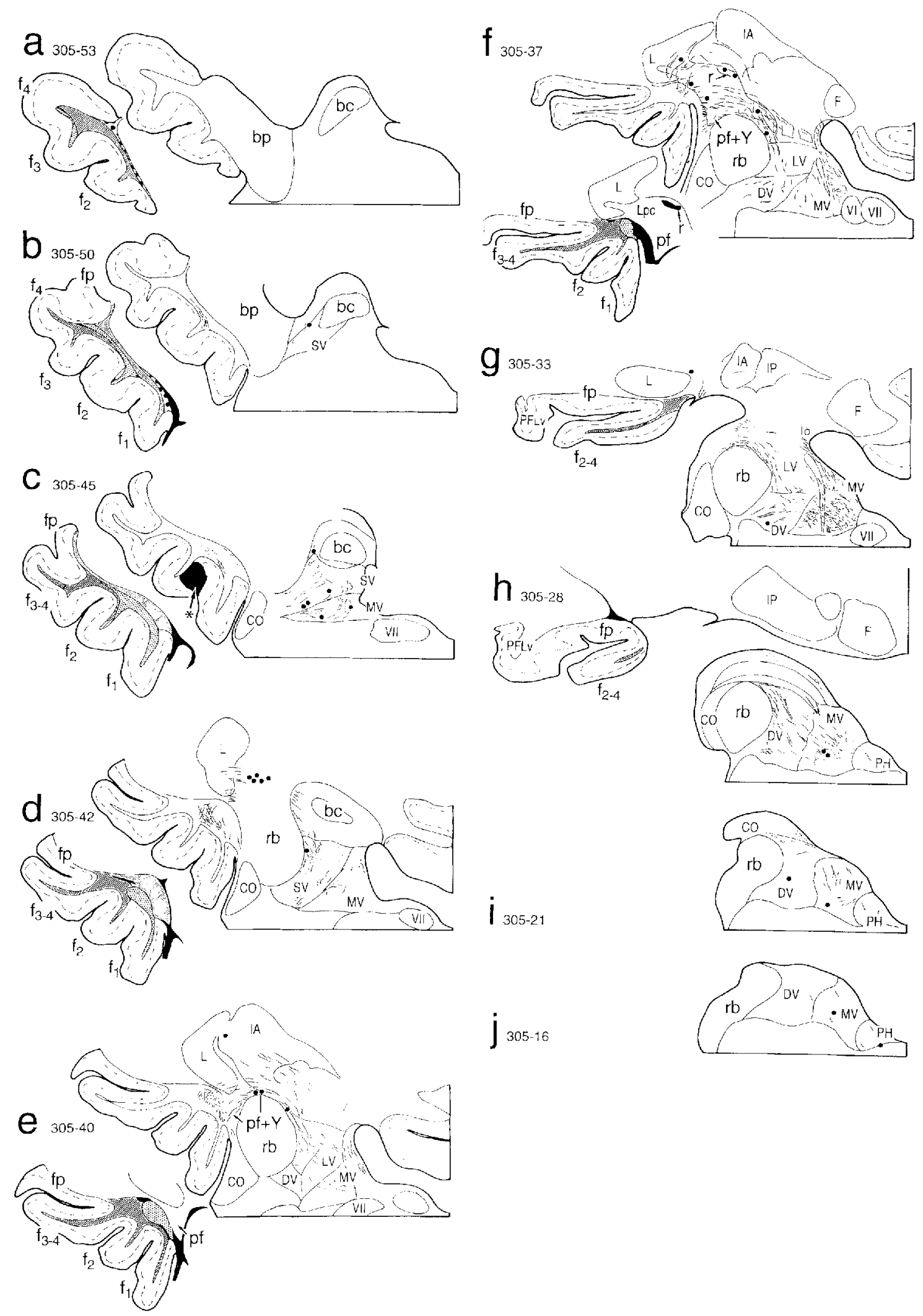

Fig. 11. a-j: Drawings of labeled fibers and neurons in transverse sections through the flocculus and brainstem in case $\mathrm{K} 305$ with an injection in $\mathrm{FZ}_{11}$. Note the location of efferent fibers in $\mathrm{FC}_{2}$ terminating almost exclusively in the MV. Same conventions as in Figure 9. 

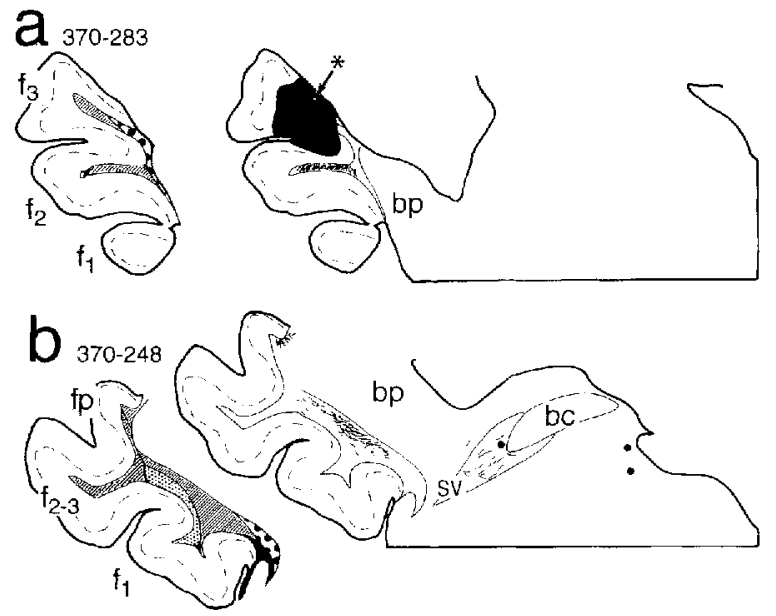

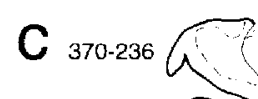
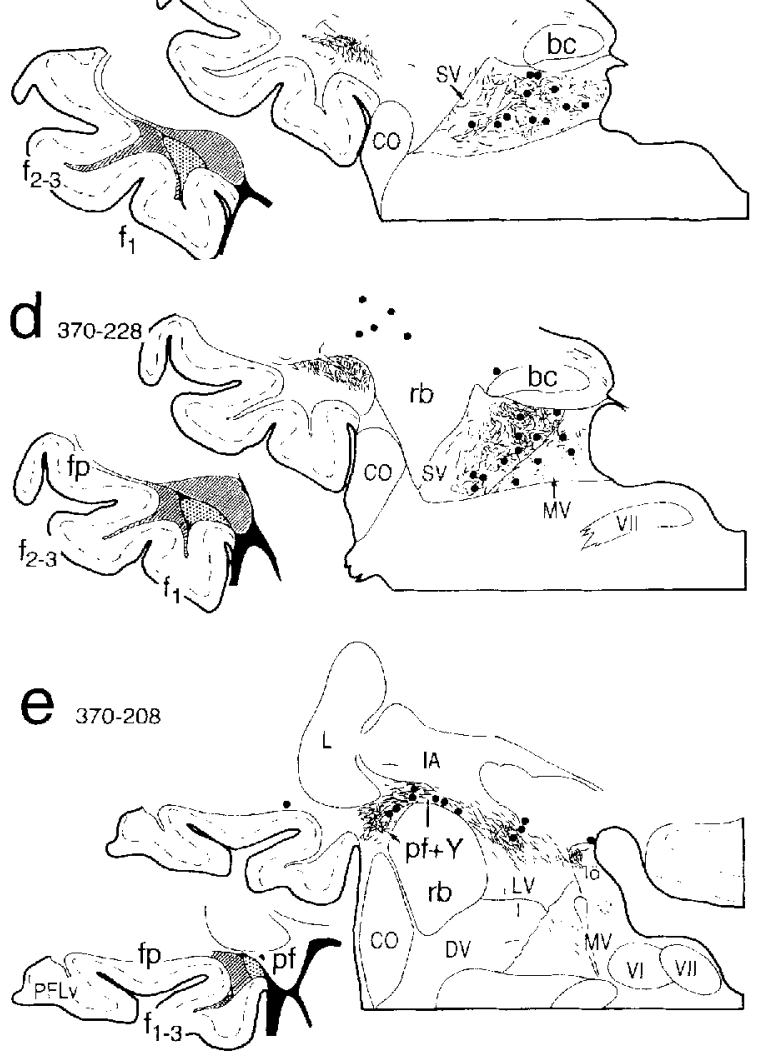

Fig. 12, a-j: Drawings of labeled fibers and neurons in transverse sections through the flocculus and brainstem in case $\mathrm{K} 370$ with an injection in $\mathrm{FZ}_{\mathrm{III}}$. Note the location of efferent fibers in $\mathrm{FC}_{3}$, their passage through the floccular peduncle and dorsal group $\mathrm{y}$, and their

al., 1977; Sato and Kawasaki, 1984, 1990a,b; Nagao et al., 1985; Belknap and Noda, 1987). Some of these studies indicated that a particular type of eye movement could only be elicited by stimulating within a confined area of the flocculus (Sato and Kawasaki, 1984, 1990a,b; Nagao et al., 1985). Recent studies (Van der Steen et al., 1991, 1994; Simpson et al., 1992) demonstrated that optimum responses were obtained by stimulating the white matter of
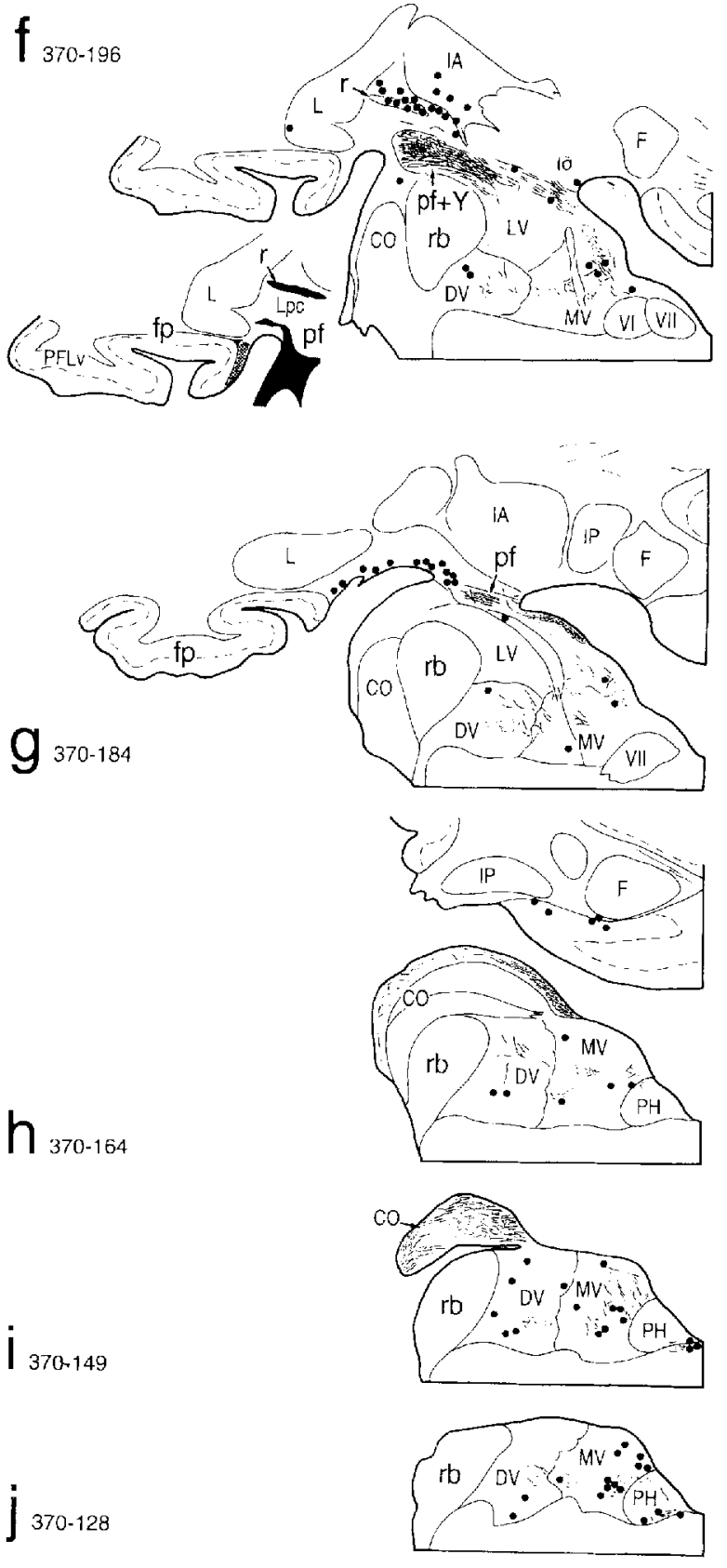

termination in the SV. Note the absence of fibers passing through the lateral cerebellar nucleus in comparison with case K 244 (Fig. 9). Same conventions as in Figure 9.

the flocculus. They verified the stimulation sites histologically, compared them with the AChE compartmentation, and found that from three of the five white matter compartments (compartments $\mathrm{FC}_{1}, \mathrm{FC}_{2}$, and $\mathrm{FC}_{3}$ ) specific classes of short-latency eye movements could be elicited. The relatively small size of compartments $\mathrm{C}_{2}$ and $\mathrm{FC}_{4}$ made it difficult to be sure that the stimulation was confined to them, and no conclusion was reached about their relation to 

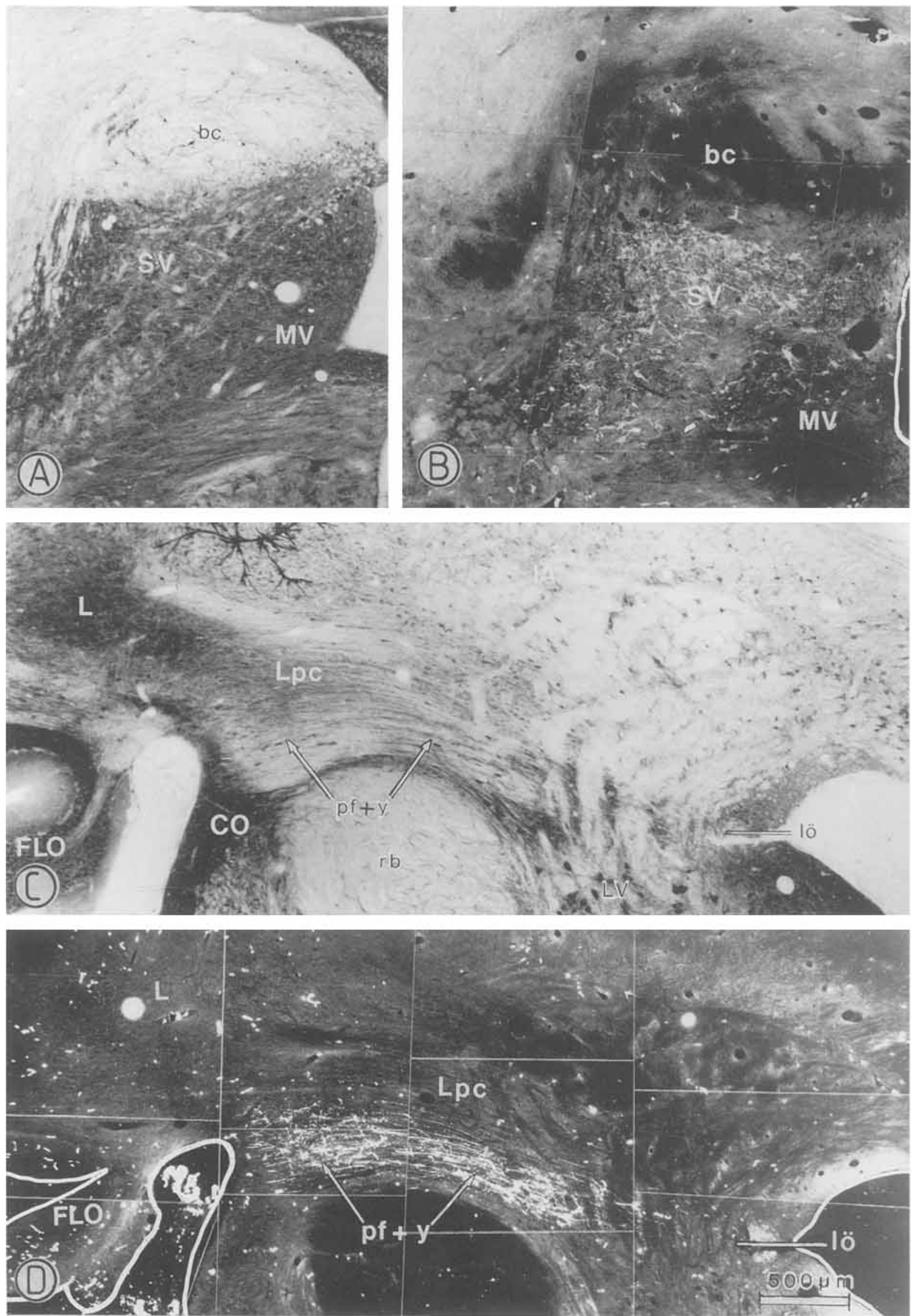

Fig. 13. Darkfield and brightfield photographs of adjacent AChEstained $(A, C)$ and TMB-processed sections (B,D) through the superior vestibular nucleus $(\mathbf{A}, \mathbf{B})$ and the floccular peduncle $(\mathbf{C}, \mathbf{D})$ in $\mathrm{K} 370$ showing accumulation of terminating fibers in the dorsolateral part of SV (B). More caudally, labeled fibers are located just dorsal to the restiform body in the floccular peduncle (D). 


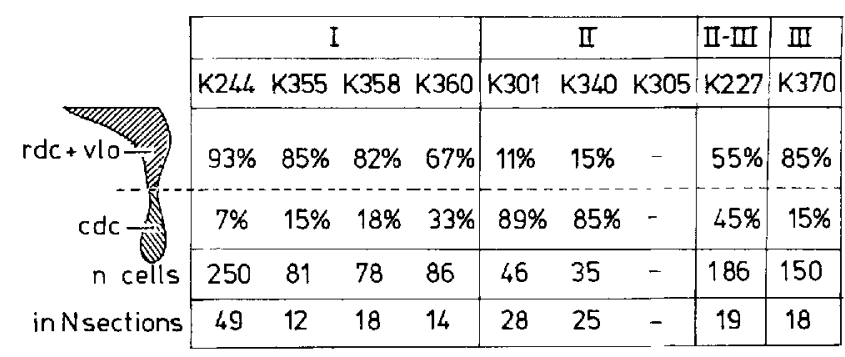

Fig. 14. Distribution of labeled cells in the caudal dorsal cap and the rostral dorsal cap with the ventrolateral outgrowth in cases with injections of wheat germ agglutinin-horseradish peroxidase (WGA$\mathrm{HRP}$ ) in floccular zones $\mathrm{FZ}_{\mathrm{I}-\mathrm{III}}$.
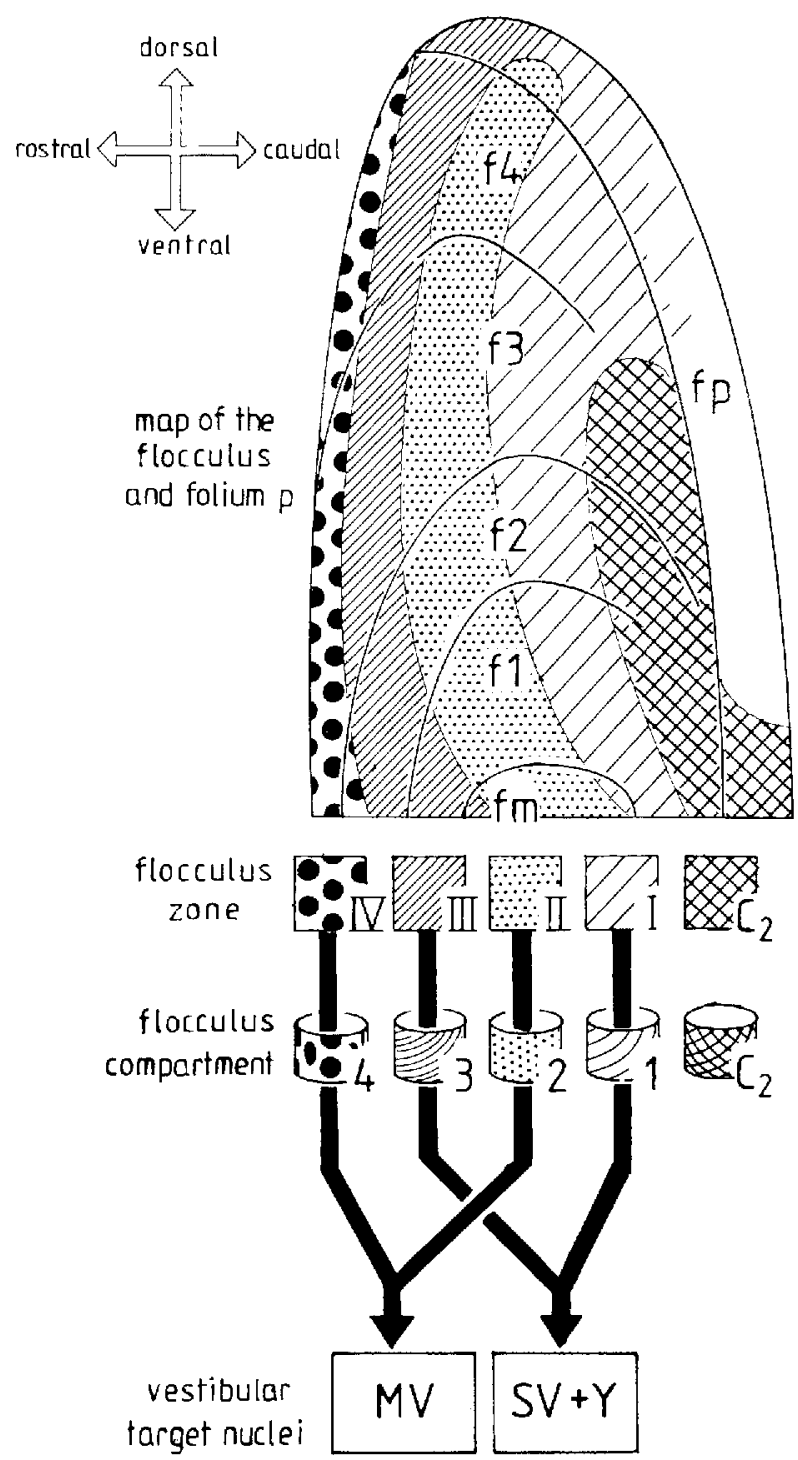

Fig. 15. Schematic diagram of the projections of floccular zones $\mathrm{FZ}_{1-\mathrm{IV}}$ through compartments $\mathrm{FC}_{1-4}$ to the vestibular nuclei. Projections of $\mathrm{FZ}_{\mathrm{I}}$ and $\mathrm{FZ}_{\mathrm{III}}$ to group y are based on De Zeeuw et al. (1992, 1994b). eye movements. Stimulation in compartments $\mathrm{FC}_{1}$ and $\mathrm{FC}_{3}$ resulted in conjugate eye movements around particular axes in the horizontal plane; the ipsilateral (left) eye moved counterclockwise around an axis at about $135^{\circ}$ to the midsagittal plane, whereas the contralateral (right) eye moved clockwise around an axis at about $45^{\circ}$ to the midsagittal plane. These compartments flanked compartment $\mathrm{FC}_{2}$, in which electrical stimulation resulted in horizontal eye movements (i.e., rotation around the vertical axis) toward the stimulated side. The results of the present study and those of Van der Steen et al. (1994) indicate that each floccular zone controls the activity of specific extraocular muscle pairs through the compartmentalized flocculovestibular nucleus projection to specific vestibulo-ocular relay neurons.

\section{ACKNOWLEDGMENTS}

The technical assistance of R.C. Boer, F.H. Klink, J. v.d. Burg, E. Dalm, and E. Goedknegt and the secretarial help of E. Klink are gratefully acknowledged.

\section{LITERATURE CITED}

Alley, K.A. (1977) Anatomical basis for interaction between cerebellar flocculus and brainstem. In R. Baker and A. Berthoz (eds): Control of Gaze by Brain Stem Neurons. Amsterdam: Elsevier, pp. 109-117.

Angaut, P, and A. Brodal (1967) The projection of the "vestibulocerebellum" onto the vestibular nuclei in the cat. Arch. Ital. Biol. 105:441-479.

Baker, R., W. Precht, and R. Llinas (1972) Cerebellar modulatory action on the vestibulotrochlear pathway in the cat. Exp. Brain Res. 15:364-385.

Balaban, C.D., and E. Watanabe (1984) Functional representation of eye movements in the flocculus of monkeys (Macaca fuscata). Neurosci. Lett. 49:199-205.

Balaban, C.D., M. Ito, and E. Watanabe (1981) Demonstration of zonal projections from the cerebellar flocculus to vestibular nuclei in monkeys (Macaca fuscata). Neurosci. Lett. 27:101-105.

Belknap, D.B., and H. Noda (1987) Eye movements evoked by microstimulation in the flocculus of the alert macaque. Exp. Brain Res. 67:352-362.

Carpenter, M.B., and R.J. Cowie (1985) Connections and aculomotor projections of the superior vestibular nucleus and cell group 'y'. Brain Res. 336:265-287.

De Zeeuw, C.I., P.L. DiGiorgi, D.R. Wylie, D. Wang, E. Marsh, and J.I. Simpson (1992) Projections of individual Purkinje cells of identified zones in the rabbit flocculus to the vestibular and cerebellar nuclei. Soc. Neurosci. Abstr. 18:854

De Zeeuw, C.I., N.M. Gerrits, J. Voogd, C.S. Leonard, and J.I. Simpson (1994a) The rostral dorsal cap and ventrolateral outgrowth of the rabbit inferior olive receive a GABAergic input from dorsal group $\mathrm{Y}$ and the ventral dentate nucleus. J. Comp. Neurol. 341:420-432.

De Zeeuw, C.I., D.R. Wylie, P.L. DiGiorgi, and J.I. Simpson (1994b) Projections of individual Purkinje cells of identified zones in the flocculus to the vestibular and cerebellar nuclei in the rabbit. J. Comp. Neurol. 349:428-447.

Dow, R.S. (1936) The fiber connections of the posterior parts of the cerebellum in the cat and rat. J. Comp. Neurol. 63:527-548.

Dow, R.S. (1938a) Efferent connections of the flocculonodular lobe in Macaca mulatia. I. Comp. Neurol. 68:297-305.

Dow, R.S. (1938b) Effects of lesions in the vestibular part of the cerebellum in primates. Arch. Neurol. Psychiatry 40:500-520.

Dufossé, M., M. Ito, and Y. Miyashita (1977) Functional localization in the rabbit's cerebellar flocculus determined in relationship with eye movements. Neurosci. Lett. 5:273-277.

Epema, A.H. (1990) Connections of the vestibular nuclei in the rabbit. Thesis. Rotterdam, The Netherlands: Erasmus University.

Epema, A.H., N.M. Gerrits, and J. Voogd (1988) Commissural and intrinsic connections of the vestibular nuclei in the rabbit: A retrograde tracer study. Exp. Brain Res. 71:129-146. 
Fukuda, J., S.M. Highstein, and M. Ito (1972) Cerebellar inhibitory control of the vestibulo-ocular reflex investigated in rabbit IIIrd nucleus. Exp. Brain Res. 14:511-526.

Gerrits, N.M., and J. Voogd (1982) The climbing fiber projection to the flocculus and adjacent paraflocculus in the cat. Neuroscience 7:29712991.

Graf, W. J.I. Simpson, and C.S. Leonard (1988) Spatial organization of visual messages of the rabbit's cerebellar flocculus. 11. Complex and simple spike responses of Purkinje cells. J. Neurophysiol. 60:2091-2121.

Graham, R.C., and M.J. Karnovsky (1966) The early stages of absorption of injected horseradish peroxidase in the proximal tubules of the mouse kidney. Ultrastructural cytochemistry by a new technique. J. Histochem. Cytochem. 14:291-302.

Graybiel, A.M., and E.A. Hartwieg (1974) Some afferent connections of the oculomotor complex in the cat: An experimental study with tracer techniques. Brain Res. 81:543-551.

Haines, D.E. (1977) Cerebellar corticonuclear and corticovestibular fibers of the floceulonodular lobe in a prosimian primate (Galago senegalensis). J. Comp. Neurol. 174:607-630.

Highstein, S.M. (1971) Organization of the inhibitory and excitatory vestibuloocular reflex pathways to the third and fourth nuclei in rabbit. Brain Res. $32 \cdot 218-224$.

Highstein, S.M. (1973) The organization of the vestibulo-ocular and trochlear reflex pathways in the rabbit. Exp. Brain Res. 17:285-300.

Highstein, S.M., and H. Reisine (1979) Synaptic and functiona) organization of vestibulo-ocular reflex pathways. Prog. Brain Res. 50:431-442.

Hirai, N., and Y. Uchino (1984) Superior vestibular neurones related to the excitatory vestibulo-ocular reflex of anterior canal origin and their ascending course in the cat. Neurasei. Res. 1:73-79.

Hwang, J.C., and W.F. Poon (1975) An electrophysiological study of the sacculoocular pathways in cats. Jpn. J. Physiol. 25:241-251.

Ito, M. (1984) The Cerebellum and Neuronal Control. New York: Raven,

Ito, M., S.M. Highstein, and J. Fukuda (1970) Cerebellar inhibition of the vestibulo-ocular reflex in rabbit and cat and its blockage by picrotoxin Brain Res. 17:524-526.

Ito, M., N. Nisimaru, and M. Yamamoto (1973) Specific neural connections for the cerebellar control of vestibulo-ocular reflexes. Brain Res. 60:238243.

Ito, M., N. Nisimaru, and M. Yamamoto (1977) Specific patterns of neuronal connections involved in the control of the rabbit's vestibulo-ocular reflexes by the cerebellar flocculus. J. Physiol. (Lond.) 265:833-854.

Ito, M., P.J. Jastreboff, and Y. Miyashita (1982a) Specific effects of unilateral lesions in the flocculus upon eye movements in albino rabbits. Exp. Brain Res. 45:233-242

Ito, M., I. Orlov, and M. Yamamoto (1982b) Topographical representation of vestibulo-ocular reflexes in rabbit cerebellar flocculus. Neuroscience 7:1644-1657.

Jansen, J., and A. Brodal (1940) Experimental studies on the intrinsic fibers of the cerebellum. II. The cortico-nuclear projection. J. Comp. Neurol. $73: 267-321$.

Kawaguchi, Y. (1985) Two groups of secondary vestibular neurons mediating horizontal canal signals, probably to the ipsilateral medial rectus muscle, under inhibitory influences from the cerebellar flocculus in rabbits. Neurosci. Res. 2:434-446.

Labandeira-Garcia, J.L., M.J. Guerra-Seijas, J.A. Labandeira-Garcia, and F.J. Jorge-Barreira (1991) Distribution of the vestibular neurons projecting to the oculomotor and trochlear nuclei in rabbits. Brain Behav. Evol. $37: 111-124$.

Langer, T. (1985) Basal interstitial nucleus of the cerebellum: Cerebellar nucleus related to the flocculus. J. Comp. Neurol. 235:38-47.

Langer, T., A.F. Fuchs, M.C. Chubb, C.A. Scudder, and S.G. Lisberger (1985) Floccular efferents in the Rhesus Macaque as revealed by autoradiography and horseradish peroxidase. J. Comp. Neurol. 235:26-37.

Lechan, R.M., J.L. Nestler, and S. Jacobson (1981) Immunohistochemical localization of retrogradely and anterogradely transported wheat germ agglutinin within the central nervous system of the rat: Application to immunostaining of a second antigen within the same neuron. J. Histochem. Cytochem. 29:1255-1262.

Leonard, C.S., J.I. Simpson, and W. Graf (1988) Spatial organization of visual messages of the rabbit's cerebellar floceulus. I. Typology of inferior olive neurons of the dorsal cap of Kooy. J. Neurophysiol. $60: 2073-2090$.

Magras, I.N., and J. Voogd (1985) Distribution of secondary vestibular fibers in the cerebellar cortex. An autoradiographic study in the cat. Acta Anat. (Basel) 123:51-57.
Mesulam, M.M. (1978) Tetramethylbenzidine for horseradish peroxidase neurohistochemistry: A non-carcinogenic blue reaction-product with superior sensitivity for visualizing neural afferents and efferents. J. Histochem. Cytochem. 26:106-117.

Nagao, S. (1983) Effects of vestibulocerebellar lesions upon dynamic characteristics and adaptation of vestibulo-ocular and optokinetic responses in pigmented rabbits. Exp. Brain Res. 53:36-46.

Nagao, S., M. Ito, and L. Karachot (1985) Eye field in the cerebellar flocculus of pigmented rabbits determined with local electrical stimulation. Neurosci. Res. 3:39-51.

Robinson, D.A. (1976) Adaptive gain control of vestibulo-ocular reflex by the cerebellum. J. Neurophysiol. 39:954-969.

Ron, S., and D.A. Robinson (1973) Eye movements evoked by cerebellar stimulation in the alert monkey. J. Neurophysiol. 36:1004-1022.

Ruigrok, 'T.J.H., R.J. Osse, and J. Voogd (1992) Organization of inferior olivary projections to the floceulus and ventral paraflocculus of the rat cerebellum. J. Comp. Neurol. 316:129-150.

Sato, $Y$., and ' $T$. Kawasaki (1984) Functional localization in the three zones related to eye movement control in the cat. Brain Res. 290:25-31.

Sato, T., and T. Kawasaki (1987) Target neurons of floccular caudal zone inhibition in y-group nucleus of vestibular nuclear complex. J. Neurophysiol. 57:460-480

Sato, Y., and T. Kawasaki (1990a) Eye movement evoked by stimulation of Purkinje cell zones of the cerebellar flocculus in the cat. Acta Med. Biol. 38:27-35.

Sato, Y., and T. Kawasaki (1990b) Operational unit responsible for planespecific control of eye movement by cerebellar flocculus in cat. J. Neurophysiol. 64:551-564.

Sato, Y., and T. Kawasaki (1991) Identification of the Purkinje cell/climbing fiber zone and its target neurons responsible for eye-movement control by the cerebellar flocculus. Brain Res. Rev. 16:39-64.

Sato, Y., T. Kawasaki, and K. Ikarashi (1982a) Zonal organization of the floccular Purkinje cells projecting to the vestibular nucleus in cats. Brain Res. 232:1-15.

Sato, Y., T. Kawasaki, and K. Ikarashi (1982b) Zonal organization of the floccular Purkinje cells projecting to the group $y$ of the vestibular complex and the lateral cerebellar nucleus in cats. Brain Res. 234:430434.

Sato, Y., T. Kawasaki, and K. Ikarashi (1983) Afferent projections from the brainstem to the three floccular zones in the cats. II. Mossy fiber projections. Brain Res. 272:37-48.

Sato, Y., F. Yamamoto, H. Shojaku, and T. Kawasaki (1984) Pathway from floccular caudal zone contributing to vertical eye-movements in cats. Role of group y nucleus of vestibular nuclei. Brain Res. 294:375-380.

Sato, Y., K. Kanda, and 'I'. Kawasaki (1988) Target neurons of floccular middle zone inhibition in the medial vestibular nucleus. Brain hes. 446:225-235.

Simpson, J.I., J. Van der Steen, and J. Tan (1992) Eye movements and the zonal structure of the rabbit flocculus. In R. Llinás and C. Sotelo (eds): The Cerebellum Revisited. New York: Springer-Verlag, pp. 255-266.

Stanton, G.B. (1980) Afferents to oculomotor nuclei from area " $y$ " in Macaca mulatta: An anterograde degeneration study. J. Comp. Neurol. 192:377-385

Tan, J., L.M. Eisenman, N.M. Gerrits, R. Hawkes, and J. Voogd (1989) Compartmentalization within the rabbit flocculus. A mabQ113 immunohistochemical, acetylcholinesterase and anatomical tracing study. Eur. J. Neurosci. Suppl. 2:33.

Tan, J., J.I. Simpson, and J. Voogd (1995a) Anatomical compartments in the white matter of the rabbit flocculus. J. Comp. Neurol. 356:1-22.

Tan, J., N.M. Gerrits, R.S. Nanhoe, J.I. Simpson, and J. Voogd (1995b) Zonal organization of the climbing fiber projection to the flocculus and nodulus of the rabbit. A combined axonal tracing and acetylcholinesterase study. J. Comp. Neurol. 356:23-50.

Thunnissen, I.E. (1990) Vestibulocerebellar and vestibulo-oculomotor relations in the rabbit. Thesis. Rotterdam, The Netherlands: Erasmus University.

Trojanowski, J.Q., J.O. Gonatas, and N.K. Gonatas (1981) Conjugates of horseradish peroxidase (HRP) with cholera toxin and wheat germ agglutinin are superior to free HRP as orthogradely transported markers. Brain Res. 223:381-385.

Van der Steen, J., J.I. Simpson, and J. Tan (199I) Representation of thrce-dimensional eye movements in the cerebellar flocculus of the rabbit. In R. Schmid and D. Zambarbieri (eds): Oculomotor Control and Cognitive Processes. Amsterdam: Elsevier, pp. 63-77. 
Van der Steen, J., J.I. Simpson, and J. Tan (1994) Functional and anatomical organization of three-dimensional eye movements in rabbit cerebellar flocculus. J. Neurophysiol. 72:31-46.

Voogd, J. (1964) The Cerebellum of the Cat. Thesis, Leiden. Assen: Van Gorcum \& Co.

Voogd, J. (1989) Parasagittal zones and compartments of the anterior vermis of the cat cerebellum. In P. Strata (ed): The Olivocerebellar System in Motor Control. Exp. Brain Res., Suppl. 17. New York: Springer Verlag, pp. 3-19.

Voogd, J., and F. Bigaré (1980) Topographical of olivary and corticonuclear fibers in the cerebellum. A review. In J. Courville, C.C. de Montigny, and Y. Lamarre (eds): The Inferior Olivary Nucleus: Anatomy and Physiology. New York: Raven Press, pp. 207-234.

Voogd, J. and H.K.P. Feirabend (1981) Classic methods in neuroanatomy. In R. Lahue (ed): Methods in Neurobiology. Vol. 2. New York: Plemum, pp. $301-365$

Voogd, J., D.T. Hess, and E. Marani (1987) The parasagittal zonation of the cerebellar cortex in cat and monkey. In J.S. King (ed): New Concepts in Cerebellar Neurobiology, Neurology and Neurobiology. Vol. 22. New York: Alan R. Liss Inc., pp. 183-220.
Yamamoto, M. (1978) Localization of rabbit's flocculus Purkinje cells projecting to the latcral cercbellar nucleus and the nucleus prepositus hypoglossi investigated by means of the horseradish peroxidase retrograde axonal transport. Neurosci. Lett. 7:197-202.

Yamamoto, M. (1979a) Topographical representation in rabbit cerebellar flocculus for various afferent inputs from the brainstem investigated by means of retrograde axonal transport of horseradish peroxidase. Neurosci. Lett. 12:29-34.

Yamamoto, M. (1979b) Vestibulo-ocular reflex pathways of rabbits and their representation in the cerebellar flocculus. In $\mathrm{R}$. Granit and $\mathrm{O}$. Pompeiano (eds): Reflex Control of Posture and Movement. Progr. Brain Res. 50:451-457. Amsterdam: Elsevier/North-Holland.

Yamamoto, M., and I. Shimoyama (1977) Differential localization of rabbit's floceulus Purkinje cells projecting to the medial and superior vestibular nuclei, investigated by means of the HRP retrograde axonal transport. Neurosti. Lett. 5:279-283.

Yamamoto, M., I. Shimoyama, and S.M. Highstein (1978) Vestibular nucleus neurons relaying excitation from the anterior canal to the oculomotor nucleus. Brain Res. 148:31-42. 